\title{
Urban background noise mapping: the multiple-reflection correction term
}

Short title: multiple-reflection correction term in noise mapping

Maarten Hornikx ${ }^{1)}$, Jens Forssén ${ }^{2)}$, Dick Botteldooren ${ }^{3)}$, Timothy van Renterghem ${ }^{3)}$, Weigang $\mathrm{Wei}^{3)}$, Mikael Ögren ${ }^{4)}$ and Erik Salomons ${ }^{5)}$

1)Building Physics and Services, Eindhoven University of Technology, P.O. box 513, $5600 \mathrm{MB}$

Eindhoven, the Netherlands. m.c.j.hornikx@tue.nl

0031-(0)402472297

2) Applied Acoustics, Chalmers University of Technology,Göteborg, Sweden.

3) Department of Information Technology, Ghent University, Ghent, Belgium

${ }^{4)}$ Department of Environmental and Traffic Analysis, VTI, Gothenburg, Sweden

${ }^{5)}$ TNO Urban Environment and Health, Delft, The Netherlands.

\begin{abstract}
Mapping of road traffic noise in urban areas according to standardized engineering calculation methods systematically results in an underestimation of noise levels at areas shielded from direct exposure to noise, such as inner yards. In most engineering methods, road traffic lanes are represented by point sources and noise levels are computed utilizing pointto-point propagation paths. For a better prediction of noise levels in shielded urban areas, an extension of engineering methods by an attenuation term $A_{\text {can }}$ has been proposed, including multiple reflections of the urban environment both in the source and in the receiver area. The present work has two main contributions for the ease of computing $A_{\mathrm{can}}$. Firstly, it is shown by numerical calculations that $A_{\text {can }}$ may be divided into independent source and receiver environment terms, $A_{\mathrm{S}}$ and $A_{\mathrm{r}}$. Based on an equivalent free field analogy, the distance dependence of these terms may moreover be expressed analytically. Secondly, an analytical expression is proposed to compute $A_{\mathrm{S}}$ and $A_{\mathrm{r}}$ for $3 \mathrm{D}$ configurations from using $2 \mathrm{D}$ configurations only. The expression includes dependence of the street width-to-height ratio, the difference in building heights and the percentage of façade openings in the horizontal plane. For the expression to be valid, the source should be separated from the receiver environment by at least four times the street width.
\end{abstract}

\section{Introduction}

According to the European Noise Directive (END) 2002/49/EC, European cities have to produce road traffic noise maps for major roads, railways and airports and exposure distributions based 
on noise levels at the façades of dwellings [1]. In addition, the END indicates that cities should quantify how many persons have access to a quiet façade, and that quiet urban areas should be protected. Current engineering methods for computing these noise maps work well for the areas directly exposed to noise, but have been shown to underestimate the levels at areas shielded from direct exposure - such as quiet façades and quiet urban areas - due to including a limited number of reflections $[2,3]$. As a result, noise mapping might lead to a too optimistic picture of the urban noise situation. Therefore, an acoustic calculation model for road traffic noise that is more suitable to predict noise levels for quiet façades has been proposed [4]. At the same time, this method should be suitable for engineering use. The proposed method therefore extends existing engineering formulae for receiver positions shielded form direct exposure. For every contributing source the suggested procedure for calculating the noise level at a shielded receiver location $\vec{x}_{r}$ per octave band reads:

$$
\begin{aligned}
& L_{\mathrm{pb}}\left(\vec{x}_{r}\right)=10 \log _{10}\left(10^{0.1 L_{p d b}}+10^{0.1 L_{p, \text { scatter }}}\right), \\
& L_{\mathrm{pdb}}\left(\vec{x}_{r}\right)=L_{\mathrm{W}}-A_{\text {free }}-A_{\mathrm{diffr}}-A_{\text {inter }}, \\
& A_{\text {diffr }}=-10 \log _{10}\left(10^{-0.1 A_{\mathrm{bar}}}+10^{-0.1 A_{\mathrm{can}}}\right) \text {, } \\
& A_{\text {can }}=A_{\mathrm{s}}+A_{\mathrm{r}} \quad \text { for } \quad\left|\vec{x}_{r, \perp}-\vec{x}_{s, \perp}\right|>x_{\mathrm{unc}},
\end{aligned}
$$

where,

- $L_{\mathrm{pb}}=$ the "background" noise level excluding the diffractions and reflections around the vertical edges and excluding the diffraction over conventional noise barriers [dB].

- $L_{\mathrm{pdb}}=$ the contribution to the "background" noise level in still homogeneous atmosphere $[\mathrm{dB}]$.

- $L_{\mathrm{W}}=$ the sound power level per octave band of a point source representing part of the $\operatorname{road}[\mathrm{dB}]$.

- $A_{\text {diffr }}=$ the total shielding attenuation by diffraction over the building roof $[\mathrm{dB}]$.

- $A_{\text {free }}=3 \mathrm{D}$ free field divergence $[\mathrm{dB}]$.

- $A_{\text {bar }}=$ the attenuation by the building(s) cutting the direct path between source and receiver limited by diffraction over the building roof, including the effect of the ground. Only the direct diffraction path without reflections in the source and receiver environments is considered $[\mathrm{dB}]$.

- $A_{\mathrm{can}}=$ the attenuation of the sound following a path between source and receiver representing multiple reflections in the source and receiver environment [dB]. 
- $A_{\mathrm{s}}=$ the attenuation of the sound following a path between source and receiver representing multiple reflections in the source environment $[\mathrm{dB}]$.

- $A_{\mathrm{r}}=$ the attenuation of the sound following a path between source and receiver representing multiple reflections in the receiver environment $[\mathrm{dB}]$.

- $A_{\text {inter }}=$ additional attenuation caused by the diffraction at intermediate canyons $[\mathrm{dB}]$.

- $L_{\mathrm{p}, \mathrm{scatter}}=$ the contribution to the background noise level caused by scattering from atmospheric turbulence [5] [dB].

- $\vec{x}_{s}=\left(x_{s}, y_{s}, z_{s}\right)=$ source coordinates $[\mathrm{m}]$.

$\vec{x}_{r}=\left(x_{r}, y_{r}, z_{r}\right)=$ receiver coordinates [m]

$\vec{x}_{s, \perp}=\left(x_{s}, y_{s}\right)=$ source coordinates in the horizontal plane [m].

$\vec{x}_{r, \perp}=\left(x_{r}, y_{r}\right)=$ receiver coordinates in the horizontal plane [m].

$x_{\mathrm{unc}}=$ distance of uncoupling $[\mathrm{m}]$.

In this paper, all terms related to $2 \mathrm{D}$ configurations are denoted by subscript $2 \mathrm{D}$, e.g. $A_{\text {can,2D }}$. Atmospheric absorption is not explicitly included in this model but is implicit in the $A_{\text {bar }}$ and $A_{\text {can }}$ terms. In the absence of multiple reflections in the source and receiver environment, $A_{\text {can }}>>A_{\text {bar }}$ and $A_{\text {bar }}$ determines $A_{\text {diffr }}$. For multiple reflections in both source and receiver environments $A_{\text {can }}<<A_{\text {bar }}$ and $A_{\text {can }}$ determines $A_{\text {diffr. }}$. An expression has been derived to compute $A_{\text {can }}$ [4], including various coefficients. For deriving these coefficients in $A_{\text {can }}$ from a range of urban configurations, detailed point-to-point calculations using a wave-based sound propagation method have been proposed [4]. However, two problems arise using $A_{\text {can }}$, which are addressed in this paper. Firstly, it is favourable in point-to-point calculations to use the uncoupled terms $A_{\mathrm{s}}$ and $A_{\mathrm{r}}$ instead of $A_{\mathrm{can}}$. Then, $A_{\mathrm{s}}$ and $A_{\mathrm{r}}$ can be assigned to source and receiver positions independently, and can be used for multiple source-receiver path calculations. For this, the distance of uncoupling $x_{\text {unc }}$ needs to be found. Furthermore, it is preferable to express the distance dependence of the terms $A_{\mathrm{S}}$ and $A_{\mathrm{r}}$ analytically. The second problem relates to the used assumptions for computing $A_{\mathrm{can}}$ in [4], being that the sound propagation in 3D can be calculated by a $2 \mathrm{D}$ cross-section configurations. Whereas $2 \mathrm{D}$ configuration calculations have been made for the sake of efficiency, a relation between the 2D and full 3D expressions for $A_{\mathrm{can}}$, and thus the independent terms $A_{\mathrm{S}}$ and $A_{\mathrm{r}}$, should be available, preferably in an analytical form. The second purpose of this paper is therefore to find an analytical expression between $A_{\mathrm{S}}$ and $A_{\mathrm{s}, 2 \mathrm{D}}$ (the latter being the 2D result of $A_{\mathrm{s}}$ ) and $A_{\mathrm{r}}$ and $A_{\mathrm{r}, 2 \mathrm{D}}$, for various urban configurations. The aimed expressions will be found through numerical computations for 2D and 3D urban configurations by using the pseudospectral time-domain method (PSTD) [6, 7]. The paper is organized as follows. In Section 2, the studied urban configurations are presented. Also, the numerical modelling approach as taken in this work is mentioned in this Section. Section 3 is 
devoted to examine the distance dependence of $A_{\mathrm{S}}$ and $A_{\mathrm{r}}$, as well as the conditions for equation (4) to hold. The analysis is made for both $2 \mathrm{D}$ as well as $3 \mathrm{D}$ configurations. The analytical expression of the $3 \mathrm{D}$ coefficients $A_{\mathrm{S}}$ and $A_{\mathrm{r}}$ as a function of their 2D counterparts is proposed in Section 4. For that purpose, 3D calculations for various typical urban configurations have been carried out. Conclusions are drawn in Section 5. The paper includes an Appendix on the accuracy of the adopted numerical approach.

\section{Configurations of study and modelling approach}

Figure 1 shows the 2D configurations studied in this paper. Urban configurations are considered, with source and receivers located in street canyons. Configuration diffr represents the canyon-to-canyon configuration with road traffic represented by a single noise source in one street canyon and receiver positions in another canyon. All façades are considered to be equal and have six depressions, corresponding to window surfaces. The other façade parts represent brickwork. Window and brickwork materials are modelled by a real normalized impedance of $Z_{n}=77$ and $Z_{n}=10$ respectively. All other surfaces are acoustically rigid. The current work is restricted to a fixed canyon height of $H=19.2 \mathrm{~m}$ (see Figure 1). For all calculations in this work, a homogeneous and non-moving medium is assumed. Using equation (3), the term $A_{\text {can,2D }}$ is here computed as:

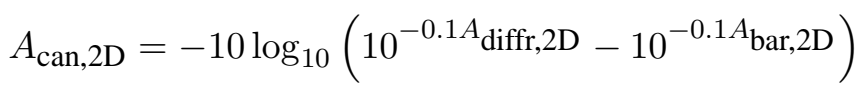

with $A_{\text {diffr,2D }}=20 \log _{10}\left|\frac{p_{\text {free, } 2 \mathrm{D}}}{p_{\text {diffr,2D }}}\right|$, with $p_{\text {free,2D }}$ the sound pressure computed in free field at distance $R_{\text {free }}=Q+W$, with $Q$ the separation distance between streets and $W$ the street width (see Figure 1a). Further $p_{\text {diffr,2D }}$ is the sound pressure computed for the 2D configuration diffr of Figure 1. The single barrier configuration, for which $A_{\mathrm{bar}, 2 \mathrm{D}}$ is computed, is also shown in Figure 1 indicated by configuration bar. The term $A_{\mathrm{can}, 2 \mathrm{D}}$ only includes contributions from source to receiver including at least one façade reflection. Further, in order to investigate whether source and receiver environment effects may be treated as being uncoupled, configurations diffr, $s$, diffr, $r$, bar, $r$ and bar,s as shown in Figure 1 are modelled to compute $A_{\text {diffr,s,2D }}, A_{\text {diffr,r,2D }}, A_{\text {bar,s,2D }}$ and $A_{\mathrm{bar}, \mathrm{r}, 2 \mathrm{D}}$, which are used similar to equation (5) to compute the attenuation terms $A_{\mathrm{s}, 2 \mathrm{D}}$ and $A_{\mathrm{r}, 2 \mathrm{D}}$ :

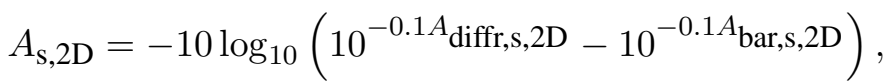

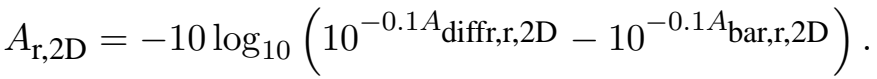

In current engineering methods, $A_{\mathrm{bar}}$ is computed by an approximate diffraction method, see e.g. reference [8]. To comply with engineering methods, the configurations of Figure 1(b) have therefore been computed by the same diffraction method. In this work, the 3D model to compute diffraction around a wedge, based on the Hadden and Pierce model for a single wedge [9], has 
been used for this purpose [10]. For the solution of the configurations in 2D, the equivalence of the diffracted sound pressure level relative to the free field level between a coherent line source and a point source, as proposed in reference [11], is used here to derive 2D solutions from 3D solutions. We note that by the used model for the barrier configurations of Figure 1(b), façades are treated as flat and rigid. A full-wave numerical method is used to compute sound pressure levels for the configurations of Figure 1(a), i.e. the PSTD method [6]. Within this method, reflection-free boundaries have been modelled by including a perfectly matched layer (PML). For some of the calculations, a hybrid computational approach is adopted for efficiency reasons. This approach divides the computational domain in a part where a numerical solution is needed and a part where an analytical solution of the wave equation is available. The accuracy of this hybrid approach is discussed in the Appendix.

Full 3D configurations of (interrupted) street canyons and courtyards are considered to relate the source and receiver environment effects to results from a 2D configuration approach. Figure 2 shows the modelled situations. The 3D results for the uninterrupted street configuration of Figures $2(\mathrm{a}, \mathrm{b})$ are obtained by a 2.5D transform as in [13], an approach based on the 2D calculations for the configurations of Figure 1(a). To evaluate the interrupted street canyon of finite length and courtyard configurations of Figures 2(c,d) and 2(e,f), a 3D PSTD model is used. The building heights and façade properties are identical to the 2D configurations. Because of symmetry, only $\frac{1}{4}$ of the interrupted street configurations has actually been modelled and only $\frac{1}{2}$ of the courtyard configurations has been modelled, see Figures 2(c,d) and 2(e,f). The interrupted street is mainly of interest for a configuration with a source in the street and receiver outside the street. The courtyard case is mainly of interest for a configuration with a receiver in the courtyard and a source outside the courtyard.

In previous work, it was found that the frequency range of interest as concerns noise from road traffic in geometrically shielded urban areas may be limited to an upper 1/3 octave band of 1.6 $\mathrm{kHz}$ [14]. For the 2D calculations, this upper limit has here been used. Due to numerical overhead of the computational model, the 3D results are evaluated with an upper 1/3 octave band of $1 \mathrm{kHz}$. Levels in the 1/3 octave bands have been computed from 20 logarithmically spaced frequencies per band. When broadband results are presented, an $A$-weighted sound power spectrum representing urban road traffic has been used, i.e. the values of $L_{\mathrm{w}}=63,75,87,95,97,104 \mathrm{~dB}$ have been used for the octave bands $32-1000 \mathrm{~Hz}$. These values have been calculated with the Dutch standard traffic noise model for typical urban traffic noise situations.

\section{Distance dependence and additivity of $A_{\mathrm{s}}$ and $A_{\mathrm{r}}$}

A first step toward the analytical expression of $A_{\mathrm{s}}=A_{\mathrm{s}}\left(A_{\mathrm{s}, 2 \mathrm{D}}\right)$ and $A_{\mathrm{r}}=A_{\mathrm{r}}\left(A_{\mathrm{r}, 2 \mathrm{D}}\right)$ is to find relations of analytical distance dependence for the separate terms $A_{\mathrm{s}, 2 \mathrm{D}}, A_{\mathrm{r}, 2 \mathrm{D}}, A_{\mathrm{S}}$ and $A_{\mathrm{r}}$. These dependencies are sought in this section, both for $2 \mathrm{D}$ as well as for 3D configurations of Figure 1. 
Also, the independence of the source and receiver terms is verified, i.e. $A_{\text {can, } 2 \mathrm{D}}=A_{\mathrm{s}, 2 \mathrm{D}}+A_{\mathrm{r}, 2 \mathrm{D}}$ and $A_{\mathrm{can}}=A_{\mathrm{s}}+A_{\mathrm{r}}$. In particular, the distance of uncoupling for which these relations are valid is searched for.

\subsection{Two-dimensional results}

\subsubsection{Distance dependence of $A_{\mathrm{s}, 2 \mathrm{D}}$ and $A_{\mathrm{r}, 2 \mathrm{D}}$}

To express the distance dependence in $A_{\mathrm{s}, 2 \mathrm{D}}$ analytically, we project $A_{\mathrm{s}, 2 \mathrm{D}}$ onto an equivalent free field situation, i.e. a source-receiver configuration in free field, see Figure 1(c). This approach assumes a distance independent part, $A_{\mathrm{s}, 2 \mathrm{D}}^{\prime}$, and a distance dependent part. We write for $A_{\mathrm{s}, 2 \mathrm{D}}^{\prime}$ and similarly $A_{\mathrm{r}, 2 \mathrm{D}}^{\prime}$ :

$$
\begin{aligned}
& A_{\mathrm{s}, 2 \mathrm{D}}\left(\vec{x}_{r}\right)=A_{\mathrm{s}, 2 \mathrm{D}}^{\prime}+10 \log _{10}\left(\frac{x_{r}-x_{\mathrm{es}, 2 \mathrm{D}}}{x_{r}}\right) . \\
& A_{\mathrm{r}, 2 \mathrm{D}}\left(\vec{x}_{r}\right)=A_{\mathrm{r}, 2 \mathrm{D}}^{\prime}+10 \log _{10}\left(\frac{x_{\mathrm{er}, 2 \mathrm{D}}}{x_{r}}\right),
\end{aligned}
$$

with $x_{r}=(Q+W) / 2$. Although $A_{\mathrm{s}, 2 \mathrm{D}}^{\prime}$ and $A_{\mathrm{r}, 2 \mathrm{D}}^{\prime}$ are considered to be distance independent, they might depend on the location of the source and receiver in the street, which is discussed in [4]. Optimal values of the equivalent source position $x_{\mathrm{es}, 2 \mathrm{D}}$ have been found by the minimizing the error $\epsilon$, which reads for $x_{\mathrm{es}, 2 \mathrm{D}}$ :

$$
\epsilon\left(x_{\mathrm{es}, 2 \mathrm{D}}\right)=\sum_{n=2}^{N}\left|\left(A_{\mathrm{s}, 2 \mathrm{D}}\left(Q_{n}\right)-A_{\mathrm{s}, 2 \mathrm{D}}\left(Q_{N}\right)+10 \log _{10}\left(\frac{x_{r, n}\left(x_{r, N}-x_{\mathrm{es}, 2 \mathrm{D}}\right)}{x_{r, N}\left(x_{r, n}-x_{\mathrm{es}, 2 \mathrm{D}}\right)}\right)\right)\right|,
$$

with $A_{\mathrm{s}, 2 \mathrm{D}}$ the broadband level, computed from using equation (6) and using the spectral distribution of $L_{\mathrm{w}}, x_{r, n}=(n Q+W) / 2$ and $N=19$. When $\epsilon\left(x_{\mathrm{es}, 2 \mathrm{D}}\right)=0, x_{\mathrm{es}, 2 \mathrm{D}}$ is found for which the distance dependence of $A_{\mathrm{s}, 2 \mathrm{D}}$ is purely analytical. It may be expected that $x_{\mathrm{es}, 2 \mathrm{D}}$ depends on $W / H$, the width-to-height ratio of the street canyon, as well as on the height of the left building relative to the right building. Results for $x_{\mathrm{es}, 2 \mathrm{D}}$ are plotted in Figure 3(a) as a function of the $W / H$ ratio. It is clear that the $W / H$ ratio has a small influence on the location of the equivalent source position. The location of $x_{\mathrm{es}, 2 \mathrm{D}}$ as a function of the height of the left building $H_{\text {left }}$ is computed for $W / H=1$, and results are shown in Figure 3(b). The results from Figure 3 are used to construct an analytical expression to compute $x_{\mathrm{es}, 2 \mathrm{D}}$ as a function of the $W / H$ ratio and the left building height $H_{\text {left }}$. We write for $x_{\mathrm{es}, 2 \mathrm{D}}$ and $x_{\mathrm{er}, 2 \mathrm{D}}$

$$
\begin{aligned}
& x_{\mathrm{es}, 2 \mathrm{D}}=\frac{W}{2}\left(1-\frac{3}{4}\left(\frac{H_{\mathrm{left}}}{H}\right)^{4}\right), \\
& x_{\mathrm{er}, 2 \mathrm{D}}=\frac{Q+W}{2}-x_{\mathrm{es}, 2 \mathrm{D}}
\end{aligned}
$$

where the coordinate origin of Figure 1(a) is respected. The relations from equations (10) are plotted in Figure 3 too by the dashed lines. Figure 4(a) shows $\Delta A_{\mathrm{s}, 2 \mathrm{D}}(Q)=A_{\mathrm{s}, 2 \mathrm{D}}(Q)-$ 
$A_{\mathrm{s}, 2 \mathrm{D}}(Q=20 W)$ and $\Delta A_{\mathrm{s}, 2 \mathrm{D}}^{\prime}(Q)$ as a function of $Q$. It illustrates that the source environment attenuation term $A_{\mathrm{s}, 2 \mathrm{D}}$ approaches a constant value for larger distances and shows that $A_{\mathrm{s}, 2 \mathrm{D}}^{\prime}$ is rather distance independent. Figure 4(b) shows $\Delta A_{\mathrm{s}, 2 \mathrm{D}}^{\prime}$ as a function of $Q$ as well as $1 / 3$ octave bands. When considering $0.5 \mathrm{~dB}$ as an acceptable error bound, we may conclude from the results that the distance dependence of $A_{\mathrm{s}, 2 \mathrm{D}}$ can be described analytically for all $1 / 3$ octave bands and $Q / W \geq 2$.

For $A_{\mathrm{r}, 2 \mathrm{D}}$, a similar equivalent free field approach as for $A_{\mathrm{s}, 2 \mathrm{D}}$ has been adopted, i.e. with a single equivalent receiver position $x_{\mathrm{er}, 2 \mathrm{D}}$ that replaces all receiver positions, see Figure 1(c) config. $r$. The source positions are equal to $x=0$ and $A_{\mathrm{r}, 2 \mathrm{D}}$ is written in equation (8), with $x_{\mathrm{er}, 2 \mathrm{D}}$ from equation (10). Figure 5(a) shows the broadband values of $\Delta A_{\mathrm{r}, 2 \mathrm{D}}$ and $\Delta A_{\mathrm{r}, 2 \mathrm{D}}^{\prime}$. The plotted results have arithmetically been averaged over all receiver positions and are very similar to the results in Figure 4(a). The results for $\Delta A_{\mathrm{r}, 2 \mathrm{D}}^{\prime}(Q=2 W)$, are plotted in Figure 5(b), showing only deviations above $0.5 \mathrm{~dB}$ for the lowest and highest frequencies.

In summary, the proposed equivalent free field representations expressed in equations (7) and (8) for the correction terms $A_{\mathrm{s}, 2 \mathrm{D}}$ and $A_{\mathrm{r}, 2 \mathrm{D}}$ yield analytical distance dependency for $Q / W \geq 2$.

\subsubsection{Additivity of $A_{\mathrm{s}, 2 \mathrm{D}}$ and $A_{\mathrm{r}, 2 \mathrm{D}}$}

As for $A_{\mathrm{s}, 2 \mathrm{D}}^{\prime}$ and $A_{\mathrm{r}, 2 \mathrm{D}}^{\prime}$ of Section 3.1.1, $A_{\mathrm{can}, 2 \mathrm{D}}^{\prime}$ may be expressed by an equivalent free field analogy, with equivalent source and receiver, see Figure 1(c). For $A_{\text {can,2D }}$, we write:

$$
A_{\mathrm{can}, 2 \mathrm{D}}\left(\vec{x}_{r, \mathrm{can}}\right)=A_{\mathrm{can}, 2 \mathrm{D}}^{\prime}+10 \log _{10}\left(\frac{x_{\mathrm{er}, \mathrm{can}, 2 \mathrm{D}}-x_{\mathrm{es}, \mathrm{can}, 2 \mathrm{D}}}{x_{\mathrm{r}, \mathrm{can}}}\right),
$$

with $x_{\mathrm{es}, \mathrm{can}, 2 \mathrm{D}}=x_{\mathrm{es}, 2 \mathrm{D}}, x_{\mathrm{er}, \mathrm{can}, 2 \mathrm{D}}=(Q+W)-x_{\mathrm{es}, 2 \mathrm{D}}$ and $x_{\mathrm{r}, \mathrm{can}}=2 x_{\mathrm{r}}=Q+W$. To verify the additivity of $A_{\mathrm{s}, 2 \mathrm{D}}$ and $A_{\mathrm{r}, 2 \mathrm{D}}$, the broadband difference $\left(A_{\mathrm{s}, 2 \mathrm{D}}^{\prime}+A_{\mathrm{r}, 2 \mathrm{D}}^{\prime}+6\right)-A_{\mathrm{can}, 2 \mathrm{D}}^{\prime}$ is computed from equations (7), (8), and (11) and is plotted in Figure 6(a) as a function of $Q$. We have added $6 \mathrm{~dB}(\mathrm{~A})$ due to a double count of the reflection at the roof level in $\left(A_{\mathrm{s}, 2 \mathrm{D}}^{\prime}+A_{\mathrm{r}, 2 \mathrm{D}}^{\prime}\right)$. The results have arithmetically been averaged over all receiver positions. The results exceed 0.5 $\mathrm{dB}(\mathrm{A})$ even for large values of $Q$. The reason is linked to the difference in the lower frequencies, see Figures 6(b). This difference can be attributed to the discrepancy between results from the Hadden and Pierce model and PSTD model for these frequencies: from an analysis for the $A_{\mathrm{diffr}, 2 \mathrm{D}}$ term, these differences were not encountered as $\left(A_{\mathrm{diffr}, \mathrm{s}, 2 \mathrm{D}}^{\prime}+A_{\mathrm{diffr}, \mathrm{r}, 2 \mathrm{D}}^{\prime}+6\right)-$ $A_{\text {diffr,2D }}^{\prime}<0.5 \mathrm{~dB}(\mathrm{~A})$ for all $Q / W \geq 2$, see Figure $6(\mathrm{~b})$. Assuming that $A_{\mathrm{can}, 2 \mathrm{D}}^{\prime}=A_{\mathrm{s}, 2 \mathrm{D}}^{\prime}+$ $A_{\mathrm{r}, 2 \mathrm{D}}^{\prime}+6, A_{\mathrm{can}, 2 \mathrm{D}}$ can be computed from $\left(A_{\mathrm{s}, 2 \mathrm{D}}+A_{\mathrm{r}, 2 \mathrm{D}}\right)$ and analytical distance dependent terms as:

$$
\begin{aligned}
& A_{\mathrm{can}, 2 \mathrm{D}}\left(\vec{x}_{\mathrm{r}, \mathrm{can}}\right)=\left(A_{\mathrm{s}, 2 \mathrm{D}}\left(\vec{x}_{r}\right)+A_{\mathrm{r}, 2 \mathrm{D}}\left(\vec{x}_{r}\right)\right)+10 \log _{10}\left(\frac{x_{\mathrm{er}, \mathrm{can}, 2 \mathrm{D}}-x_{\mathrm{es}, \mathrm{can}, 2 \mathrm{D}}}{x_{\mathrm{r}, \mathrm{can}}}\right)+6 \\
& \text { for } \quad Q \geq 2 W
\end{aligned}
$$

Figure 6(b) shows the spectral agreement of $\left(A_{\mathrm{s}, 2 \mathrm{D}}^{\prime}+A_{\mathrm{r}, 2 \mathrm{D}}^{\prime}+6\right)$ and $A_{\mathrm{can}, 2 \mathrm{D}}^{\prime}$ for $Q=20 W$. The result of $\left(A_{\mathrm{bar}, \mathrm{s}, 2 \mathrm{D}}^{\prime}+A_{\mathrm{bar}, \mathrm{r}, 2 \mathrm{D}}^{\prime}+6\right)$ and $A_{\mathrm{bar}, 2 \mathrm{D}}^{\prime}$ are also shown, illustrating the dominance of $A_{\text {can,2D }}^{\prime}$ regarding the $A_{\text {diffr,2D }}^{\prime}$ term. 
In summary, for the $2 \mathrm{D}$ configurations, $Q \geq 2 W$ seems to be a good choice for $x_{\text {unc }}$ of equation $(4)$.

\subsection{Three-dimensional results}

\subsubsection{Distance dependence of $A_{\mathrm{s}}$ and $A_{\mathrm{r}}$}

A similar analysis as for the $2 \mathrm{D}$ configurations is undertaken for the $3 \mathrm{D}$ configuration of an uninterrupted street, i.e. the configurations of Figure 1 where streets have an infinite length as depicted in Figures 2(a,b). We here limit the study to $y_{s}=y_{r}=0$. For $A_{\mathrm{s}}$ and $A_{\mathrm{r}}$, we write:

$$
\begin{aligned}
& A_{\mathrm{s}}\left(\vec{x}_{r}\right)=A_{\mathrm{s}}^{\prime}+20 \log _{10}\left(\frac{x_{\mathrm{r}}-x_{\mathrm{es}}}{x_{\mathrm{r}}}\right), \\
& A_{\mathrm{r}}\left(\vec{x}_{r}\right)=A_{\mathrm{r}}^{\prime}+20 \log _{10}\left(\frac{x_{\mathrm{er}}}{x_{\mathrm{r}}}\right) .
\end{aligned}
$$

Similar to the 2D configurations, the optimal values of the equivalent source positions are computed and are shown in Figure 7. As concerns the $W / H$-dependence and the dependence on $H_{\text {left }}$, the similarity between the 2D results of Figure 3 is obvious. The location of the equivalent sources is however different from the locations in 2D, with smaller values of $x_{\mathrm{es}}$ compared to its $2 \mathrm{D}$ counterparts. A relation for $x_{\mathrm{es}}$ and $x_{\mathrm{er}}$ is derived from the numerical results of Figure 7:

$$
\begin{aligned}
& x_{\mathrm{es}}=\frac{W}{3}\left(1-\frac{4}{5}\left(\frac{H}{W}\right)\right)-\frac{7}{5}\left(\frac{H_{\text {left }}}{H}\right)^{3 / 2}, \\
& x_{\mathrm{er}}=\frac{Q+W}{2}-x_{\mathrm{es}}
\end{aligned}
$$

and is shown by the dashed lines in Figure 7. The attenuation terms $\Delta A_{\mathrm{S}}$ and $\Delta A_{\mathrm{S}}^{\prime}$ are plotted in Figure 8(a), and $\Delta A_{\mathrm{s}}^{\prime}$ is plotted as a function of frequency and distance $Q$ in Figure 8(b). For the receiver environment, the values of $\Delta A_{\mathrm{r}}$ and $\Delta A_{\mathrm{r}}^{\prime}$ are plotted in Figure 9(a). The importance of splitting the attenuation terms $A_{\mathrm{S}}$ and $A_{\mathrm{r}}$ into a distance dependent and distance independent term is highlighted by the Figures: whereas $A_{\mathrm{s}}$ and $A_{\mathrm{r}}$ slowly converge with distance, the terms $A_{\mathrm{S}}^{\prime}$ and $A_{\mathrm{r}}^{\prime}$ show to be distance independent for $Q / W \geq 4$ within the $0.5 \mathrm{~dB}(\mathrm{~A})$ error. Figure 9(b) shows $\Delta A_{\mathrm{r}}^{\prime}(4 Q)$, showing that in contrast to the $2 \mathrm{D}$ configuration however, a higher receiver position dependence of $\Delta A_{\mathrm{r}}^{\prime}$ is noticeable.

The proposed free field representation expressed in equation (13) and (14) thus return an expressions for the correction terms $A_{\mathrm{S}}$ and $A_{\mathrm{r}}$, which have an analytical dependence on the distance for $Q / W \geq 4$.

\subsubsection{Additivity of $A_{\mathrm{s}}$ and $A_{\mathrm{r}}$}

To verify the additivity of $A_{\mathrm{S}}$ and $A_{\mathrm{r}}$ in the 3D configuration of uninterrupted streets, an analogue analysis as for the 2D configuration has been carried out. In Figure 10(a), broadband results are 
shown for the differences $\left(A_{\mathrm{s}}^{\prime}+A_{\mathrm{r}}^{\prime}+6\right)-A_{\mathrm{can}}^{\prime}$ and $\left(A_{\mathrm{s}}+A_{\mathrm{r}}+6\right)-A_{\mathrm{can}}$. The primed numbers do not converge to a value within $0.5 \mathrm{~dB}(\mathrm{~A})$ for large values of $Q / W$. This is similar as what was found for the 2D configuration and also has the same explanation. Figure 10(b) also shows the dominance of $A_{\mathrm{can}}^{\prime}$ over $A_{\mathrm{bar}}^{\prime}$. From the equality of the primed numbers, we now can compute $A_{\text {can }}$ as:

$$
\begin{aligned}
& A_{\text {can }}\left(\vec{x}_{\mathrm{r}, \mathrm{can}}\right)=\left(A_{\mathrm{S}}\left(\vec{x}_{r}\right)+A_{\mathrm{r}}\left(\vec{x}_{r}\right)\right)+20 \log _{10}\left(\frac{x_{\text {er,can }}-x_{\text {es,can }}}{x_{r}}\right)+6 \\
& \quad \text { for } \quad Q \geq 2 W .
\end{aligned}
$$

\section{2D versus 3D approach}

In Section 3, we have found distance dependence expressions for $A_{\mathrm{s}, 2 \mathrm{D}}, A_{\mathrm{r}, 2 \mathrm{D}}, A_{\mathrm{S}}$ and $A_{\mathrm{r}}$ and the conditions for which they are valid. Also, the expressions for $A_{\text {can,2D }}$ as well $A_{\text {can }}$ based on the separate source and receiver environment terms have been derived. The objective of this section is to find expressions for the 3D attenuation terms as a function of their $2 \mathrm{D}$ counterpart. The analysis is based on three types of configurations: 1) an uninterrupted street of infinite length of Figures 2(a,b), 2) a finite-length street interrupted by a cross street, see Figures 2(c,d), and 3) a courtyard, see Figures 2(e,f). As road traffic is represented by point sources along the street, the effect of a horizontal directionality of attenuation terms $A_{\mathrm{S}}$ and $A_{\mathrm{r}}$ is low when including contributions from all sources in the street. The here adopted approach is therefore to use attenuation terms that are angular averaged values in the horizontal plane, further denoted by $\bar{A}_{\mathrm{s}}$ and $\bar{A}_{\mathrm{r}}$. In this section, we thus search for the relations $\bar{A}_{\mathrm{s}}=\bar{A}_{\mathrm{s}}\left(A_{\mathrm{s}, 2 \mathrm{D}}\right)$ and $\bar{A}_{\mathrm{r}}=\bar{A}_{\mathrm{r}}\left(A_{\mathrm{r}, 2 \mathrm{D}}\right)$.

\subsection{Uninterrupted Street}

For the uninterrupted street of Figures 2(a,b), we first examine the equivalence between 2D and $3 \mathrm{D}$ results where $y_{s}=y_{r}=0$. We exploit the hypothesis that the $2 \mathrm{D}$ and $3 \mathrm{D}$ expressions only deviate through distance dependence, and that the distance independent coefficients are equal, i.e. $A_{\mathrm{r}}^{\prime} \approx A_{\mathrm{r}, 2 \mathrm{D}}^{\prime}, A_{\mathrm{s}}^{\prime} \approx A_{\mathrm{s}, 2 \mathrm{D}}^{\prime}$ and $A_{\mathrm{can}}^{\prime} \approx A_{\mathrm{can}, 2 \mathrm{D}}^{\prime}$. To verify this hypothesis, Figure 11 shows results of the broadband differences between $2 \mathrm{D}$ and $3 \mathrm{D}$ terms, averaged over the receiver positions. All results are consistent in showing clear deviations and a slow convergence with distance for the unprimed numbers, and deviations smaller than $0.5 \mathrm{~dB}(\mathrm{~A})$ for the primed numbers for all distances above $Q / W \geq 3$, which supports the used equalities $A_{\mathrm{r}}^{\prime}=A_{\mathrm{r}, 2 \mathrm{D}}^{\prime}$, $A_{\mathrm{s}}^{\prime}=A_{\mathrm{s}, 2 \mathrm{D}}^{\prime}$ and $A_{\mathrm{can}}^{\prime}=A_{\mathrm{can}, 2 \mathrm{D}}^{\prime}$ for $Q / W \geq 3$. To verify whether $\bar{A}_{\mathrm{s}}^{\prime}=A_{\mathrm{s}, 2 \mathrm{D}}^{\prime}$ holds for the uninterrupted street, the configurations with $y_{r} \neq 0, y_{s}=0$ are now investigated. Figure 12 shows the broadband attenuation terms $A_{\mathrm{s}, 2 \mathrm{D}}^{\prime}$ and $A_{\mathrm{s}}^{\prime}(\theta)$ results for $Q=19 W$ as a function of the angle $\theta$, with equivalent sources according to equations (10) and (15). The $3 \mathrm{D}$ results for the barrier configuration have been computed with a Hadden and Pierce model where the diffraction 
edge is perpendicular to the source-receiver direction, which is according to the approach in standard engineering methods [8]. Results show a decease in attenuation term $A_{\mathrm{s}}^{\prime}$ with increasing angle $\theta$, i.e. a lower shielding. The equality $\bar{A}_{\mathrm{s}}^{\prime}=A_{\mathrm{s}, 2 \mathrm{D}}^{\prime}$, with $\bar{A}_{\mathrm{s}}^{\prime}=1 / 85 \int_{0}^{85} A_{\mathrm{s}}^{\prime}(\theta) \mathrm{d} \theta$, is clearly not valid within the $0.5 \mathrm{~dB}(\mathrm{~A})$ error bound and should be altered into $\bar{A}_{\mathrm{s}}^{\prime}=B_{s} A_{\mathrm{s}, 2 \mathrm{D}}^{\prime}$. An expression for $B_{\mathrm{S}}$ will be derived in the following Section 4.2.

\subsection{Interrupted street}

Streets have a finite length and most streets are interrupted by cross streets or openings. As for the uninterrupted street case, we use the relation $\bar{A}_{\mathrm{s}}^{\prime}=B_{s} A_{\mathrm{s}, 2 \mathrm{D}}^{\prime}$, where $B_{\mathrm{s}}$ is expected to deviate from 1. The studied configuration of interrupted streets is shown in Figures 2(c,d). We aim to derive an expression for $B_{\mathrm{S}}$ for these cases. Three locations of the cross street with respect to the main street, denoted by $U$, and two cross street widths, denoted by $C$, are investigated. The broadband results $A_{\mathrm{S}}^{\prime}$ (up to the $1 \mathrm{kHz} 1 / 3$ octave band) are plotted as a function of the angle in Figure 13, along with the results for the barrier attenuation term $A_{\mathrm{bar}, \mathrm{s}}^{\prime}$, and results for the uninterrupted infinitely long street of Section4.1, $A_{\mathrm{s}, 2 \mathrm{D}}^{\prime}$ and $A_{\mathrm{s}}^{\prime}$. Equations (10) and (15) have been used to determine the equivalent source positions. For angles above $70^{\circ}$, Figure 13 shows that all values of $A_{\mathrm{s}}^{\prime}$ increase for the finite street configuration, with large deviations from the results for the uninterrupted infinitely long street. The impact of the cross street increases with increasing cross street width, and with decreasing distance of the cross street to the source position. The configuration denoted as $C 2 U 1$, i.e. $C=W$ and $U=W / 2$ indeed shows largest deviations from the uninterrupted street. For this $C 2 U 1$ case, results between $20^{\circ}$ and $55^{\circ}$ do show values of $A_{\mathrm{s}}^{\prime} \approx A_{\mathrm{bar}, \mathrm{s}}^{\prime}$, implying a slight effect compared to the single diffraction case. To quantify the effect of openings in the façades, the relative number $S=\frac{\left(A_{\mathrm{bar}, \mathrm{s}}^{\prime}\left(\theta=0^{\circ}\right)-\bar{A}_{\mathrm{s}}^{\prime}\right)}{\left(A_{\mathrm{bar}, \mathrm{s}}^{\prime}\left(\theta=0^{\circ}\right)-A_{\mathrm{s}, \mathrm{D}}^{\prime}\right)}$ is plotted in Figure 14 for the various interrupted street configurations of Figures 2(c,d), with $\bar{A}_{\mathrm{S}}^{\prime}$ the averaged value of $A_{\mathrm{S}}^{\prime}$ over angles $0^{\circ}-85^{\circ}$. The result for the uninterrupted infinitely long street of Section4.1 is also included. $S$ indicates the value of the $\bar{A}_{\mathrm{s}}^{\prime}$, relative to $A_{\mathrm{bar}, \mathrm{s}}^{\prime}\left(\theta=0^{\circ}\right)$ and $A_{\mathrm{s}, 2 \mathrm{D}}^{\prime}$ : a value of $S=0$ implies that $\bar{A}_{\mathrm{s}}^{\prime}=A_{\mathrm{bar}, \mathrm{s}}^{\prime}\left(\theta=0^{\circ}\right)$ and a value of $S=1$ means $\bar{A}_{\mathrm{S}}^{\prime}=A_{\mathrm{s}, 2 \mathrm{D}}^{\prime}$. A clear trend is visible of a decreasing value of $S$ with an increasing value of $p$, the angular fraction of open façades in the horizontal plane as seen from the source. A relationship of $S=C_{1} *\left(1-p^{C_{2}}\right)$ is derived from numerical data, with $C_{1}=1.26, C_{2}=0.6$. Utilizing this expression for $S$, we find for the coefficient $B_{\mathrm{s}}$ :

$$
B_{s}=\frac{A_{\mathrm{bar}, \mathrm{s}}^{\prime}\left(\theta=0^{\circ}\right)}{A_{\mathrm{s}, 2 \mathrm{D}}^{\prime}}(1-S)+S,
$$

with

$$
S=C_{1} *\left(1-p^{C_{2}}\right) \text {. }
$$

The sought relations $\bar{A}_{\mathrm{s}}=\bar{A}_{\mathrm{s}}\left(A_{\mathrm{s}, 2 \mathrm{D}}\right)$ and $\bar{A}_{\mathrm{r}}=\bar{A}_{\mathrm{r}}\left(A_{\mathrm{r}, 2 \mathrm{D}}\right)$ can now be written as: 


$$
\begin{aligned}
\bar{A}_{\mathrm{s}}\left(\vec{x}_{r}\right) & =B_{\mathrm{S}} A_{\mathrm{s}, 2 \mathrm{D}}^{\prime}+20 \log _{10}\left(\frac{\left|\vec{x}_{\mathrm{r}, \perp}\right|-x_{\mathrm{es}}}{\left|\vec{x}_{\mathrm{r}, \perp}\right|}\right) \\
& =B_{\mathrm{S}} \underbrace{\left(A_{\mathrm{s}, 2 \mathrm{D}}-10 \log _{10}\left(\frac{\left|\vec{x}_{\mathrm{r}, \perp}\right|-x_{\mathrm{es}, 2 \mathrm{D}}}{\left|\vec{x}_{\mathrm{r}, \perp}\right|}\right)\right)}_{A_{\mathrm{s}, 2 \mathrm{D}}^{\prime} \approx A_{\mathrm{s}}^{\prime}}+20 \log _{10}\left(\frac{\left|\vec{x}_{\mathrm{r}, \perp}\right|-x_{\mathrm{es}}}{\left|\vec{x}_{\mathrm{r}, \perp}\right|}\right) \\
\bar{A}_{\mathrm{r}}\left(\vec{x}_{r}\right) & =B_{\mathrm{r}} A_{\mathrm{r}, 2 \mathrm{D}}^{\prime}+20 \log _{10}\left(\frac{x_{\mathrm{er}}}{\left|\vec{x}_{\mathrm{r}, \perp}\right|}\right) \\
& =B_{\mathrm{r}} \underbrace{\left(A_{\mathrm{r}, 2 \mathrm{D}}-10 \log _{10}\left(\frac{x_{\mathrm{er}, 2 \mathrm{D}}}{\left|\vec{x}_{\mathrm{r}, \perp}\right|}\right)\right)}_{A_{\mathrm{r}, 2 \mathrm{D}}^{\prime} \approx A_{\mathrm{r}}^{\prime}}+20 \log _{10}\left(\frac{x_{\mathrm{er}}}{\left|\vec{x}_{\mathrm{r}, \perp}\right|}\right) .
\end{aligned}
$$

\subsection{Courtyard}

The value of $B_{r}$ is finally verified for a typical configuration of the receiver environment: a closed courtyard configuration as depicted in Figures 2(e,f). This configuration represents a situation with an angular fraction of open façades in the horizontal plane equal to $p=0$. A single receiver is positioned at a height of $4.7 \mathrm{~m}$ in the middle of the courtyard. Equations (15) have been used to determine the equivalent receiver positions. Figure 15 shows broadband angular dependent results of $A_{\mathrm{r}}^{\prime}(\theta)$ at $Q=40 \mathrm{~W}$ for the two courtyard configurations, along with the $2 \mathrm{D}$ results $A_{\mathrm{r}, 2 \mathrm{D}}^{\prime}$ and $B_{\mathrm{r}} A_{\mathrm{r}, 2 \mathrm{D}}^{\prime}$ for the cross-section where $\theta=0^{\circ}$, with $B=0.64$ as computed from equation (17). The angular dependency for the courtyard cases is rather weak. The angular averaged values $\bar{A}_{\mathrm{r}}^{\prime}$ are $8.0 \mathrm{~dB}(\mathrm{~A})$ and $7.1 \mathrm{~dB}(\mathrm{~A})$ for courtyard configurations with $T=W / 2$ and $T=3 W / 2$ respectively. These values are closer to the $2 \mathrm{D}$ results of $A_{\mathrm{r}, 2 \mathrm{D}}^{\prime}$ than to $B_{\mathrm{r}} A_{\mathrm{r}, 2 \mathrm{D}}^{\prime}$, implying that the courtyard situations lead to a stronger attenuation term $\bar{A}_{\mathrm{r}}^{\prime}$ than the infinitely long street case. Clearly, with increasing $T$ the $\bar{A}_{\mathrm{r}}^{\prime}=0.64 A_{\mathrm{r}, 2 \mathrm{D}}^{\prime}$ would apply here too.

\section{Conclusions}

A recently proposed improved engineering method for urban areas shielded from direct exposure to traffic noise includes $A_{\text {can }}$, a term that accounts for multiple reflections of the built environment in the source and receiver area. The proposed term relies on point-to-point calculations using a wave-based acoustic propagation method for 2D urban canyon geometries, and may be split in a term accounting for reflections in the source environment $A_{\mathrm{s}}$, and a term accounting for reflections in the receiver environment, $A_{\mathrm{r}}$. In this work, an expression is derived to compute the full 3D $A_{\text {can }}$ term from the 2D results, further relying on analytical terms only. For this purpose, $2 \mathrm{D}$ and $3 \mathrm{D}$ calculations with a wave-based calculation model have been carried out for various urban configurations. First, expressions have been derived to compute the 2D and 3D attenuation terms of the source and receiver environment $-A_{\mathrm{s}, 2 \mathrm{D}}, A_{\mathrm{r}, 2 \mathrm{D}}, A_{\mathrm{s}}$ and $A_{\mathrm{r}}-$ into a distance 
independent term and a analytical term for the distance dependence. These expressions rely on equivalent free field analogies. The expressions were shown to be valid for source-to-receiver environment distances exceeding twice the street canyon width $(\mathrm{Q}=2 \mathrm{~W})$ in $2 \mathrm{D}$, and exceeding 4 times the street canyon width in 3D. Furthermore, it indeed was shown to be possible to compute $A_{\mathrm{can}}$ and $A_{\mathrm{can}, 2 \mathrm{D}}$ from these separate source and receiver environment terms, when correcting for the distance dependence using analytical expressions. To express the 3D attenuation term by the 2D terms, we have proposed a 3D term that represent an averaged value over the horizontal angles. The final expressions, i.e. equations (18) and (19), enable to compute the 3D attenuation term for multiple reflections, from the 2D attenuation term, including analytical terms for distance dependence. For application to a wider range of configurations, the difference between the width-to-height ratio of the streets and height of the left building are incorporated in the equation, as well as the angular fraction of street openings. The model can also be used for closed courtyards. It is important to emphasize that the presented expression in equations (18) and (19) are valid for the configuration as used in this paper. Also, the results of this work rely on values averaged of the receiver positions, and does not reflect the local differences between receiver positions. The latter is in incorporated in the distance independent coefficients, which is subject of another paper.

\section{Acknowledgements}

Part of this work was made possible by financial support by the Life+ program of the European Community (project QSIDE, LIFE09 ENV/NL/000423).

\section{A Accuracy of the Kirchhoff-Helmholtz integral approach}

Far field sound propagation for calculation of the configurations diffr,s and diffr, $r$ of Figure 1 are in this work computed using the Kirchhoff-Helmholtz $(\mathrm{KH})$ integral technique as depicted in Figure 16 for the configuration diffr,s. The PSTD method is used to solve the wave equation in the left part of Figure 16(b), and pressure and normal velocity components are stored at the vertical line at $x=W / 2+2 \mathrm{~m}$. Then, the solution in the latter part is computed by applying the Kirchhoff-Helmholtz (KH) integral method to the vertical line at $x=W / 2+2$ $\mathrm{m}$, as depicted in Fig. 16(b). The KH method is described e.g. by Pierce [12]. This integral method relies on Green's functions, which are known at the right side of the vertical line at $x=W / 2+2 \mathrm{~m}$. With this hybrid approach, a higher numerical efficiency is obtained compared to applying the PSTD method to the complete domain. The 3D results for the uninterrupted street configuration of Figures 2 (a,b) are obtained by a 2.5D transform as in [13], an approach based on 2D calculations. A three step approach is then adopted: 1) a 2D PSTD calculation, 2) the KH-integral approach for far field results, 3) the 2.5D transform to obtain 3D results. For 
the 3D configurations of Figure 2(c,e), far field results are also obtained by integrating over the solution at the KH-planes. For the interrupted street case, the KH-planes vertically range from $H$ to $H+z_{\mathrm{KH}}$ and we assume a single hard ground surface outside the KH-planes.

The accuracy of the KH-approach is here investigated for an analytical case of a source over a rigid ground surface for $2 \mathrm{D}$ and $3 \mathrm{D}$ configurations, see Figures $17(\mathrm{a}, \mathrm{b}, \mathrm{e}, \mathrm{f})$, with horizontal dimensions of the configurations according to the 2D configuration diffr,s, the 3D interrupted street configuration of Figures 2(c,d) and the courtyard configuration with $T=3 \mathrm{~W} / 2$ of Figures 2(e,f). The solution at the KH-plane $x_{\mathrm{KH}}$, computed with PSTD, is tapered near the top by a super-Gaussian window to avoid diffraction from the edge when integrating over the KH-plane, i.e. for the pressure in the $2 \mathrm{D}$ configuration:

$$
p\left(x_{\mathrm{KH}}, z\right)=\left\{\begin{aligned}
G\left(x_{\mathrm{KH}}, z \mid 0,0\right) e^{-\alpha\left(z-z_{0}\right)^{6}} & \text { for } \quad z_{0}<z<z_{\mathrm{KH}} \\
G\left(x_{\mathrm{KH}}, z \mid 0,0\right) & \text { for } 0<z<z_{0},
\end{aligned}\right.
$$

with $G\left(x_{\mathrm{KH}}, z \mid 0,0\right)$ the 2D Green's function from the source to the KH-plane and $z_{0}=0.7 z_{\mathrm{KH}}$. We evaluate the KH-integral with 10 points per wavelength. Since the PSTD calculations have a spatial resolution of 2 points per smallest wavelength, spectral interpolation has been applied at the KH-plane prior to evaluation of the far field results. For the 2D configuration, Figures $17(\mathrm{c}, \mathrm{d})$ show the error as a function of the $1 / 3$ octave band with $z_{\mathrm{KH}}=30 \mathrm{~m}$, for $W=19.2$ $\mathrm{m}$ and $W=19.2 / \cos \left(\theta=80^{\circ}\right)$ respectively. The latter corresponds to a projected street width for the uninterrupted street case configuration of Figure 12, with $\theta=80^{\circ}$. For $W=19.2 \mathrm{~m}$, errors are below $0.5 \mathrm{~dB}$ for all distances and $1 / 3$ octave bands. For $W=19.2 / \cos \left(80^{\circ}\right)$, a larger error is retrieved for the lower $1 / 3$ octave bands. As most results in this paper rely on broadband values, and since the $A$-weighted power spectrum is dominant for the highest $1 / 3$ octave band, the broadband error will be small for $\theta=80^{\circ}$ too.

For the 3D configurations, results are shown in Figures $17(\mathrm{~g}, \mathrm{~h})$ for the interrupted street and courtyard configurations respectively as a function of the $1 / 3$ octave band and as a function of the angle $\theta$ for $x_{r, \perp}=20 W$, with $W=H$. For both the street and the courtyard configuration, the error increases with angle, since $y_{\mathrm{KH}}>x_{\mathrm{KH}}$. Similar remarks as for the $2 \mathrm{D}$ error hold.

The value of $z_{\mathrm{KH}}=30 \mathrm{~m}$ has been used for all calculations in this paper.

\section{References}

[1] Directive 2002/49/EC of the European Parliament and of the Council relating to the assessment and management of environmental noise (2002).

[2] M. Ögren, M., W. Kropp: Road traffic noise propagation between two dimensional city canyons using an equivalent source approach. Acta Acust. United Ac. 90 (2004) 293-300. 
[3] T. Kihlman, M. Ögren, W. Kropp: Prediction of urban traffic noise in shielded courtyards. Proceedings of The International Congress and Exposition on Noise Control Engineering, Dearborn, MI, USA, (2002).

[4] W. Wei, T. Van Renterghem, D. Botteldooren, M. Hornikx, J. Forssén, E. Salomons, M. Ögren: Urban background noise mapping: the general model. Manuscript in preparation for submission to Acta Acust. United Ac. (2013).

[5] J. Forssén, M. Hornikx, T. Van Renterghem, W. Wei, D. Botteldooren, M. Ögren.:Urban background noise mapping: the turbulence scattering model. Manuscript in preparation for submission to Acta Acust. United Ac, 2013.

[6] M. Hornikx, R. Waxler, J. Forssén: The extended Fourier pseudospectral time-domain method for atmospheric sound propagation. J. Acoust. Soc. Am. 128 (2010) 297-319.

[7] M. Hornikx, J. Forssen: Modelling of sound propagation to three-dimensional urban courtyards using the extended Fourier PSTD method. Appl. Acoust. 72 (2011) 665-676.

[8] E. Salomons, D. van Maercke, J. Defrance, F. de Roo: The Harmonoise Sound Propagation Model. Acta Acust. United Ac. 972011 62-74.

[9] J.D. Hadden, A.D. Pierce: Sound diffraction around screens and wedges for arbitrary point source locations. J. Acoust. Soc. Am. 69 (1981) 1266-1276. Erratum, J. Acoust. Soc.Am. 71 (1982) 1290.

[10] E. Salomons: Sound propagation in complex outdoor situations with a non-refracting atmosphere: Model based on analytical solutions for diffraction and reflection. Acta Acust. United Ac. 83 (1997) 436-454.

[11] T. Van Renterghem, E. Salomons, D. Botteldooren: Efficient FDTD-PE model for sound propagation in situations with complex obstacles and wind profiles. Acta Acust. United Ac. 91 (2005) 671-679.

[12] A.D. Pierce: Acoustics, an introduction to its physical principles and applications. The Acoustical Society of America, Melville, NY, USA (1981).

[13] M. Hornikx, J. Forssén: The 2.5-dimensional equivalent sources method for directly exposed and shielded urban canyons. J. Acoust. Soc. Am. 122 (2007) 2532-2541.

[14] T. Van Renterghem, D. Botteldooren: The importance of roof shape for road traffic noise shielding in the urban environment. J. Sound and Vibration 329 (2010) 1422-1434. 


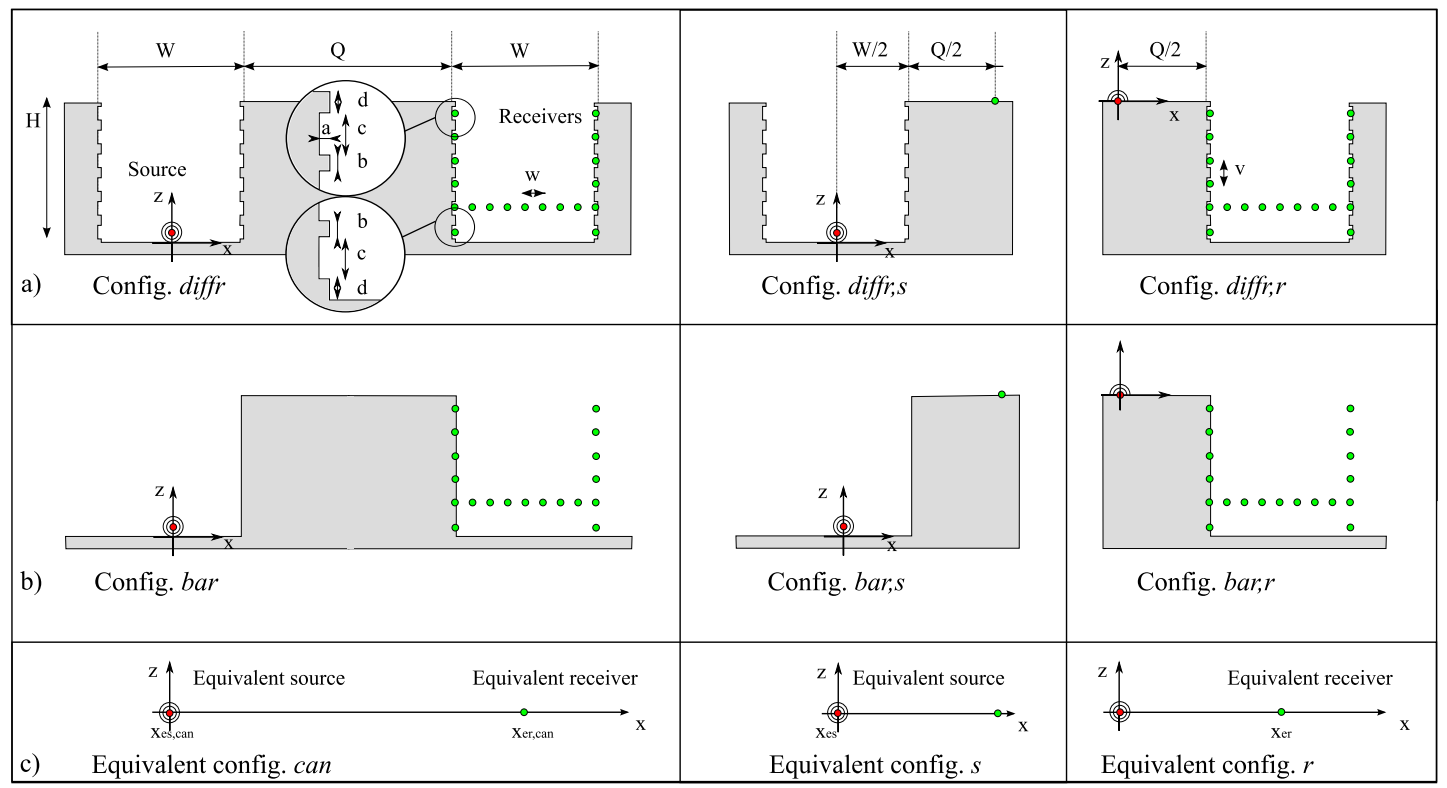

Figure 1: Configurations studied with numerical parameters $a=0.16 \mathrm{~m}, b=0.64 \mathrm{~m}, c=1.92$ $\mathrm{m}, d=1.28 \mathrm{~m}, v=c+d=3.2 \mathrm{~m}, w=1.6 \mathrm{~m}, z_{s}=0.5 \mathrm{~m}, W=19.2 \mathrm{~m}, H=19.2 \mathrm{~m}, Q$ is variable. (a) configurations for which the shielding attenuation terms $A_{\mathrm{diffr}}, A_{\mathrm{diffr}, \mathrm{s}}$ and $A_{\mathrm{diffr}, \mathrm{r}}$ apply, (b) configurations for which the barrier attenuation terms $A_{\mathrm{bar}}, A_{\mathrm{bar}, \mathrm{s}}$ and $A_{\mathrm{bar}, \mathrm{r}}$ apply, (c) equivalent configurations for which the shielding attenuation terms $A_{\mathrm{can}}, A_{\mathrm{s}}$ and $A_{\mathrm{r}}$ apply. 
a)

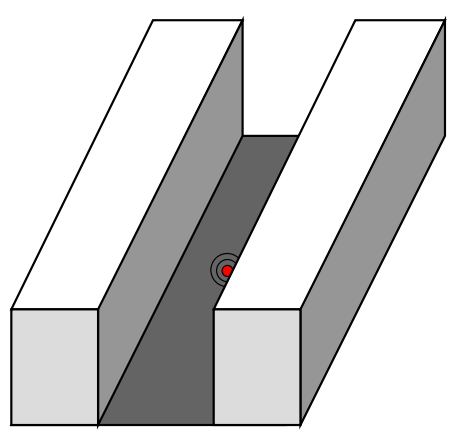

b)

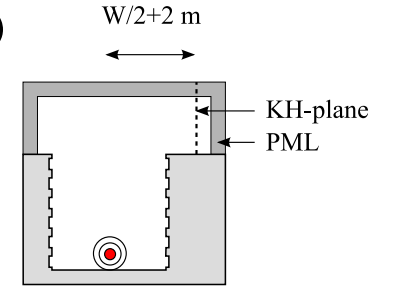

c)

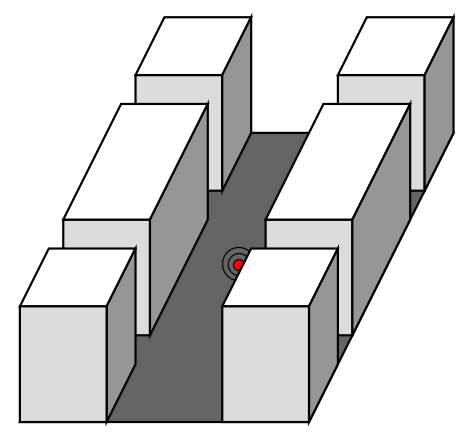

e)
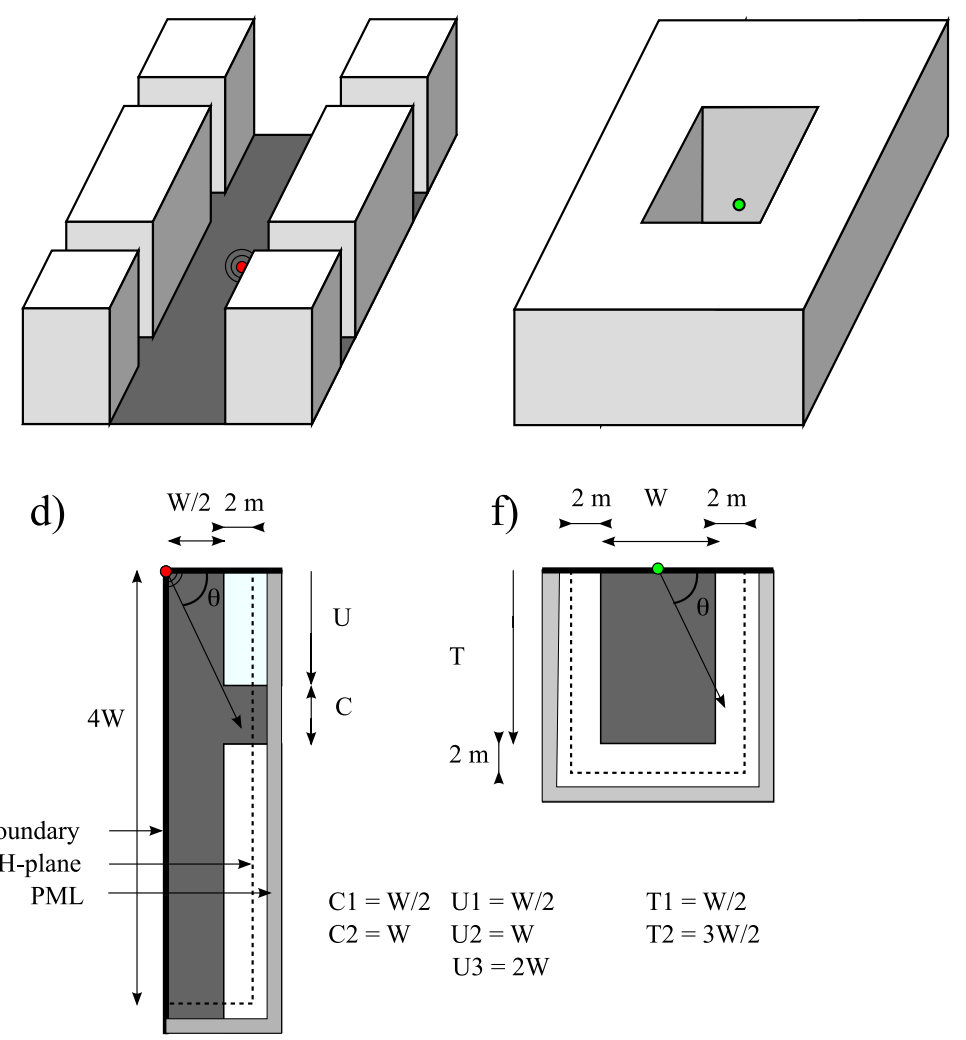

Figure 2: 3D configurations studied, a) Graphical representation infinite street, b) Computational approach shown by cross section at $y=0$. A $2.5 \mathrm{D}$ transform is applied to the $2 \mathrm{D}$ results. c) Graphical representation of finite street with cross streets, d) Computational approach shown by top view, e) Graphical representation of courtyard, f) Computational approach shown by top view. 


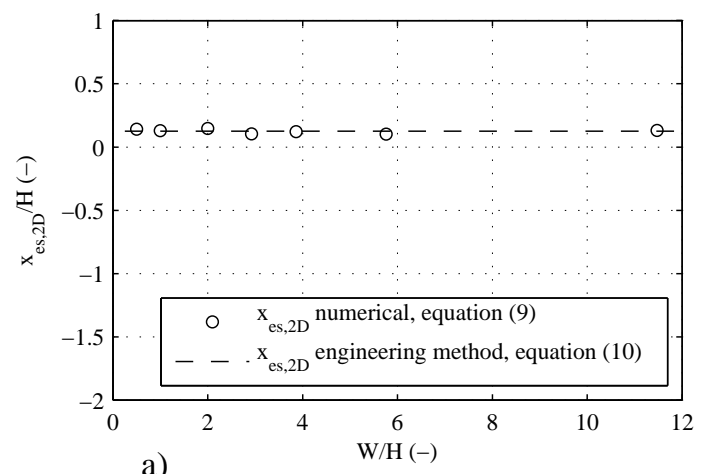

a)

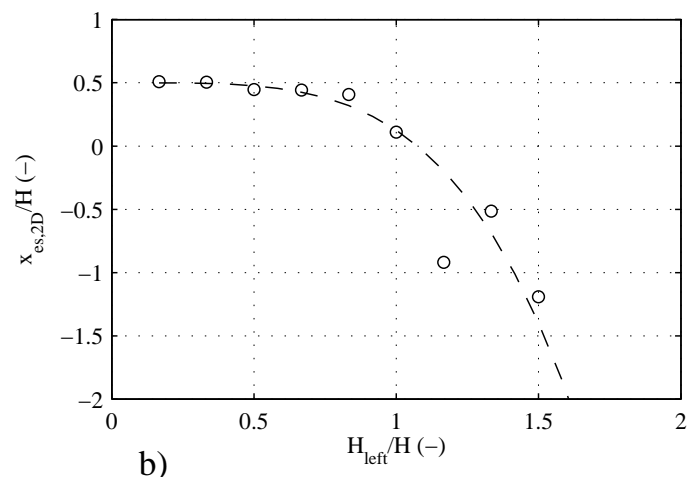

b)

Figure 3: Values of the equivalent source position $x_{\mathrm{es}, 2 \mathrm{D}}$ for attenuation term $A_{\mathrm{s}, 2 \mathrm{D}}^{\prime}$, a) as a function of the canyon width $W$ with $H=19.2 \mathrm{~m}, \mathrm{~b}$ ) as a function of the left building height $H_{\text {left }}$ with $W=19.2 \mathrm{~m}$.

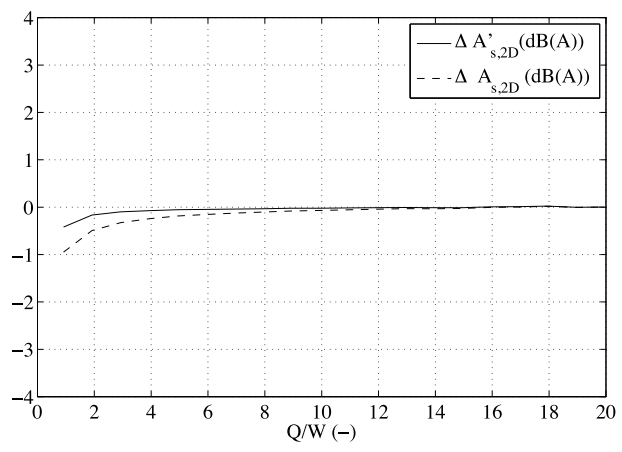

a)

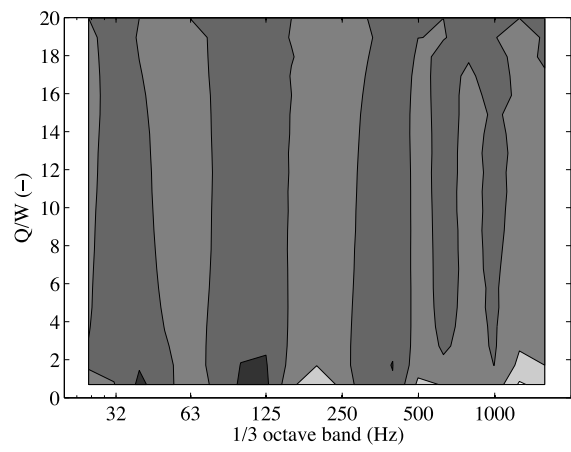

b)

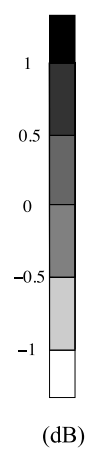

(dB)

Figure 4: Attenuation terms computed from configurations diffr,s and bar,s of Figure 1, a) $\Delta A_{\mathrm{s}, 2 \mathrm{D}}$ and $\Delta A_{\mathrm{s}, 2 \mathrm{D}}^{\prime}$ in $\left.\mathrm{dB}(\mathrm{A}), \mathrm{b}\right) \Delta A_{\mathrm{s}, 2 \mathrm{D}}^{\prime}$.

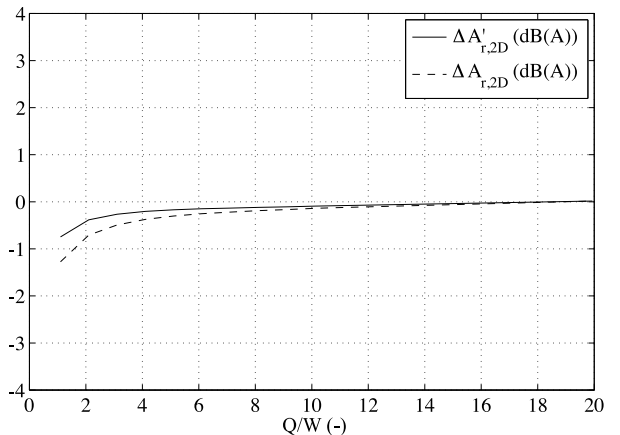

a)

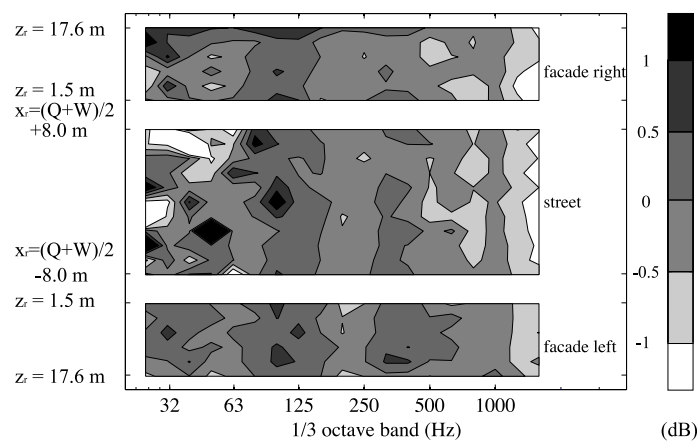

b)

Figure 5: Attenuation terms computed from configurations diffr, $r$ and bar, $r$ of Figure 1, a) $\Delta A_{\mathrm{r}, 2 \mathrm{D}}^{\prime}$ and $\Delta A_{\mathrm{r}, 2 \mathrm{D}}$, averaged over all receiver positions, b) $\Delta A_{\mathrm{r}, 2 \mathrm{D}}^{\prime}(Q=2 W)$ as a function of the receiver position and third octave bands. 


$$
\begin{aligned}
& -\mathrm{A}_{\mathrm{s}, 2 \mathrm{D}}^{\prime}+\mathrm{A}_{\mathrm{r}, 2 \mathrm{D}}^{\prime}+6-\mathrm{A}_{\mathrm{can}, 2 \mathrm{D}}^{\prime}(\mathrm{dB}(\mathrm{A})) \\
& --\mathrm{A}_{\mathrm{s}, 2 \mathrm{D}}+\mathrm{A}_{\mathrm{r}, 2 \mathrm{D}}+6-\mathrm{A}_{\mathrm{can}, 2 \mathrm{D}}(\mathrm{dB}(\mathrm{A})) \\
& -\mathrm{A}_{\mathrm{diffr}, \mathrm{s}, 2 \mathrm{D}}^{\prime}+\mathrm{A}_{\mathrm{diffr}, \mathrm{r}, 2 \mathrm{D}}^{\prime}+6-\mathrm{A}_{\mathrm{diffr}, \mathrm{can}, 2 \mathrm{D}}^{\prime}(\mathrm{dB}(\mathrm{A})) \\
& \mathbf{-} \cdot \mathrm{A}_{\mathrm{diffr}, \mathrm{s}, 2 \mathrm{D}}+\mathrm{A}_{\mathrm{diffr}, \mathrm{r}, 2 \mathrm{D}}+6-\mathrm{A}_{\mathrm{diffr}, \mathrm{can}, 2 \mathrm{D}}(\mathrm{dB}(\mathrm{A}))
\end{aligned}
$$

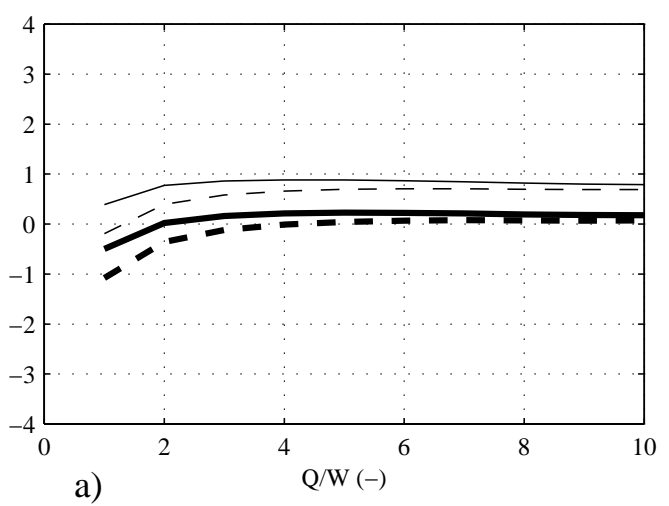

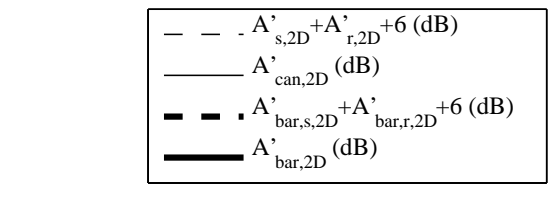

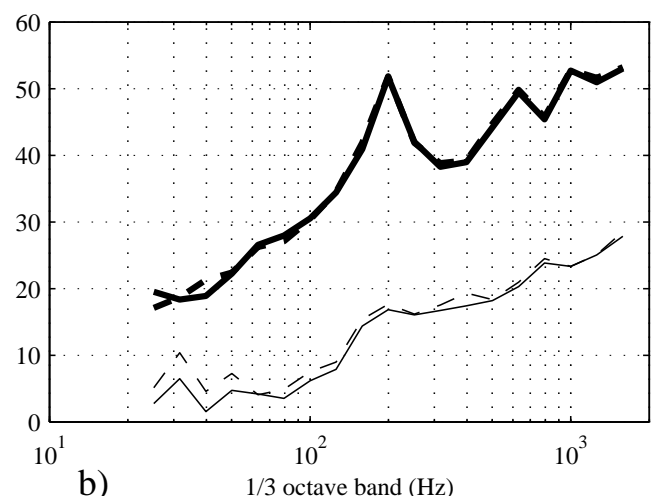

Figure 6: a) Broadband error of splitting the attenuation term $A_{\mathrm{can}, 2 \mathrm{D}}^{\prime}$ into $A_{\mathrm{s}, 2 \mathrm{D}}^{\prime}+A_{\mathrm{r}, 2 \mathrm{D}}^{\prime}$, and $A_{\text {can,2D }}$ into $A_{\mathrm{s}, 2 \mathrm{D}}+A_{\mathrm{r}, 2 \mathrm{D}}$. Results have been averaged over all receiver positions, b) Results at $Q=10 \mathrm{~W}$ averaged over all receiver positions. 

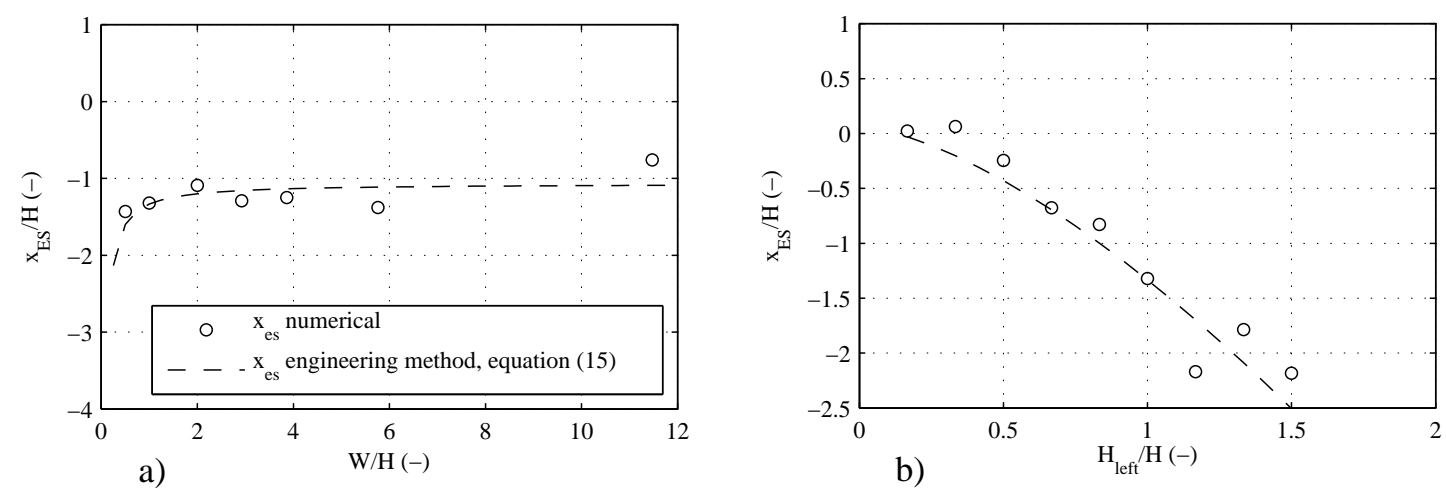

Figure 7: Values of the equivalent source position $x_{\mathrm{es}}$ for $3 \mathrm{D}$ attenuation term $A_{\mathrm{s}}^{\prime}$ for configuration (a) of Figure 2 and $y_{r}=0 \mathrm{~m}$, as a function of the canyon width $W$ with $H=19.2 \mathrm{~m}, \mathrm{~b}$ ) as a function of the left building height $H_{\text {left }}$ with $W=19.2 \mathrm{~m}$.

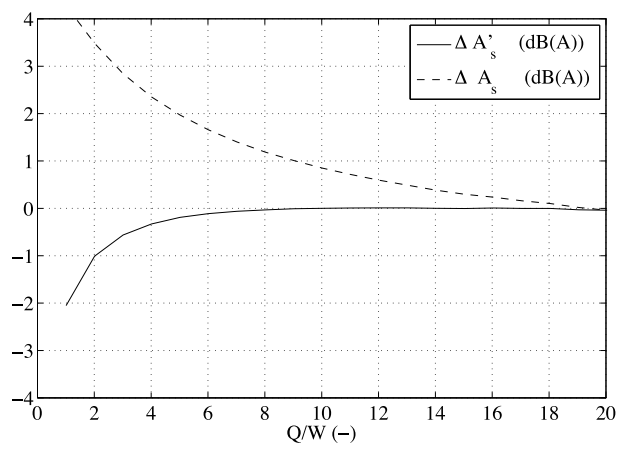

a)

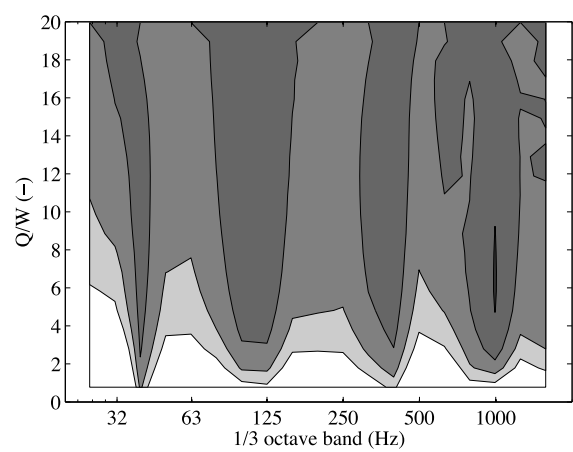

b)

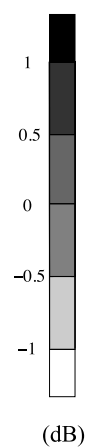

(dB)

Figure 8: Attenuation terms computed from configurations diffr,s and bar,s of Figure 1, a) $\Delta A_{\mathrm{S}}$ and $\Delta A_{\mathrm{s}}^{\prime}$ in $\left.\mathrm{dB}(\mathrm{A}), \mathrm{b}\right) \Delta A_{\mathrm{s}}^{\prime}$.

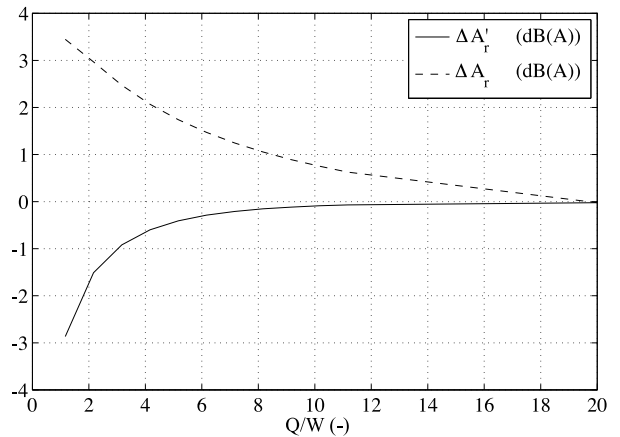

a)

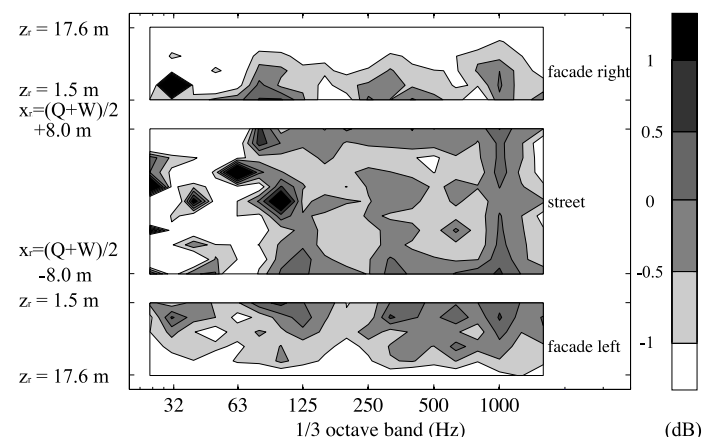

b)

Figure 9: Attenuation terms computed from configurations diffr, $r$ and bar, $r$ of Figure 1, a) $\Delta A_{\mathrm{r}}^{\prime}$ and $\Delta A_{\mathrm{r}}$, averaged over all receiver positions, b) $\Delta A_{\mathrm{r}}^{\prime}(Q=4 W)$ as a function of the receiver position and third octave bands. 


$$
\begin{aligned}
& -\mathrm{A}_{\mathrm{s}}^{\prime}+\mathrm{A}_{\mathrm{r}}^{\prime}+6-\mathrm{A}_{\text {can }}^{\prime}(\mathrm{dB}(\mathrm{A})) \\
& -\ldots \mathrm{A}_{\mathrm{s}}+\mathrm{A}_{\mathrm{r}}+6-\mathrm{A}_{\text {can }}(\mathrm{dB}(\mathrm{A})) \\
& -\mathrm{A}_{\text {diffr, } \mathrm{s}}^{\prime}+\mathrm{A}_{\text {diffr, } \mathrm{r}}^{\prime}+6-\mathrm{A}_{\text {diffr,can }}^{\prime}(\mathrm{dB}(\mathrm{A})) \\
& \text { - - . } \mathrm{A}_{\text {diffr, }, \mathrm{s}}^{\prime}+\mathrm{A}_{\text {diffr, } \mathrm{r}}^{\prime}+6-\mathrm{A}_{\text {diffr,can }}^{\prime}(\mathrm{dB}(\mathrm{A}))
\end{aligned}
$$

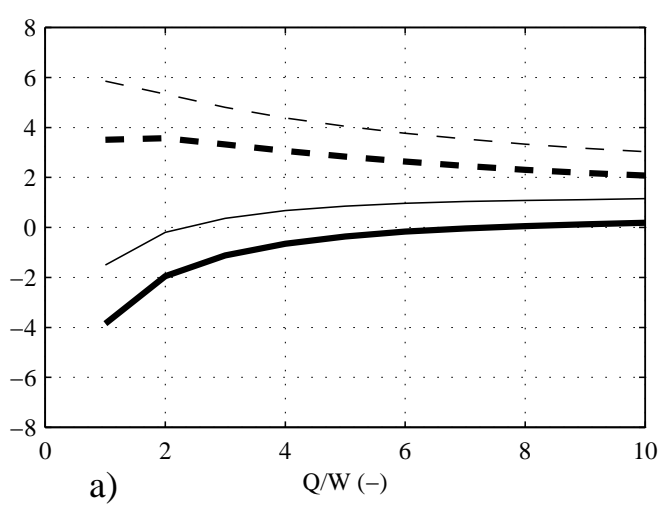

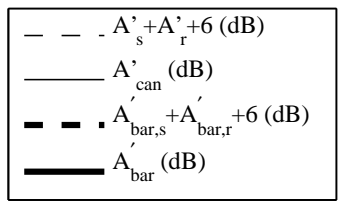

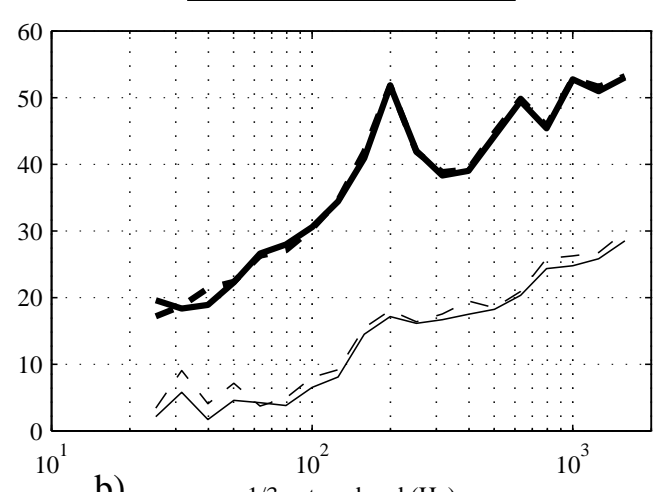

b)

$1 / 3$ octave band $(\mathrm{Hz})$

Figure 10: a) Broadband error of splitting the attenuation term $A_{\mathrm{can}}^{\prime}$ into $A_{\mathrm{s}}^{\prime}+A_{\mathrm{r}}^{\prime}$, and $A_{\mathrm{can}}$ into $A_{\mathrm{s}}+A_{\mathrm{r}}$. Results have been averaged over all receiver positions, b) Results at $Q=(10 \mathrm{~W})$ averaged over all receiver positions.

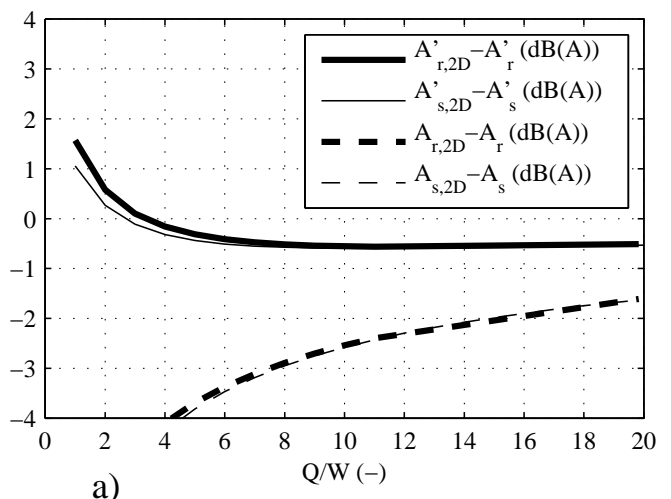

a)

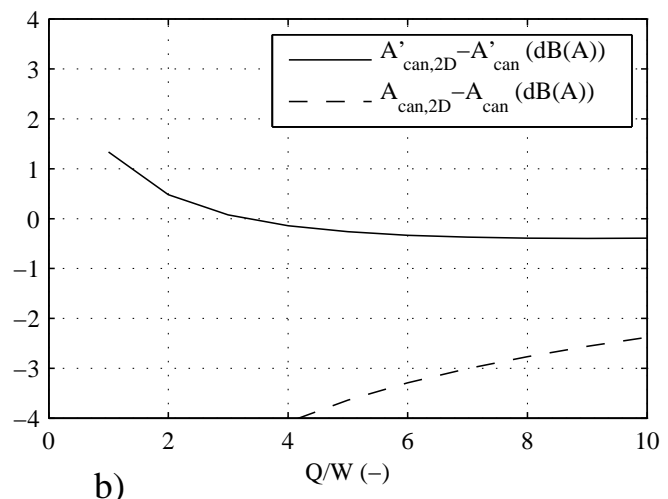

b)

Figure 11: Broadband difference between 2D and 3D attenuation terms. Results have been averaged over all receiver positions, a) separate source and receiver environment terms, b) total canyon term. 


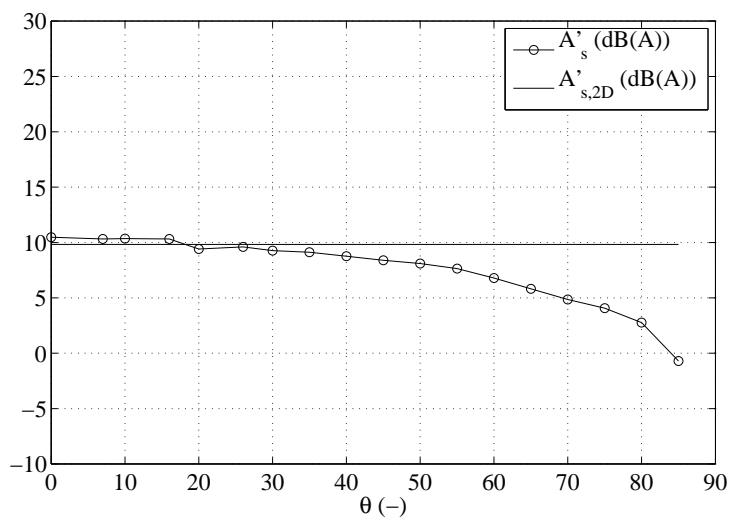

Figure 12: Broadband results of $A_{s}^{\prime}$ at $Q=19 \mathrm{~W}$ up to $1.6 \mathrm{kHz}$ for configuration of Figure 2(a).

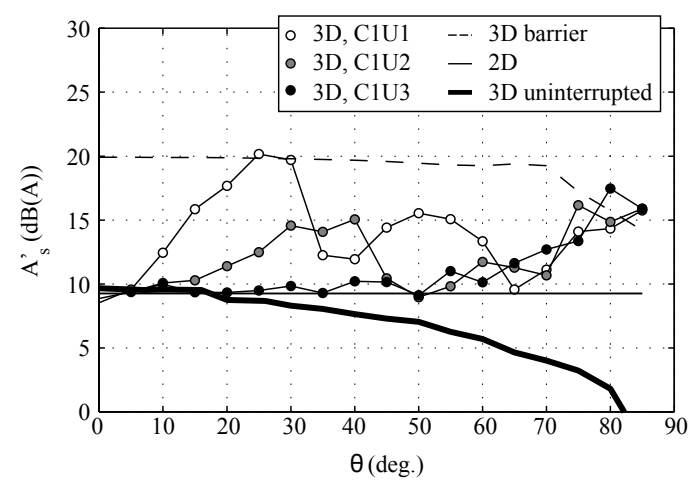

a)

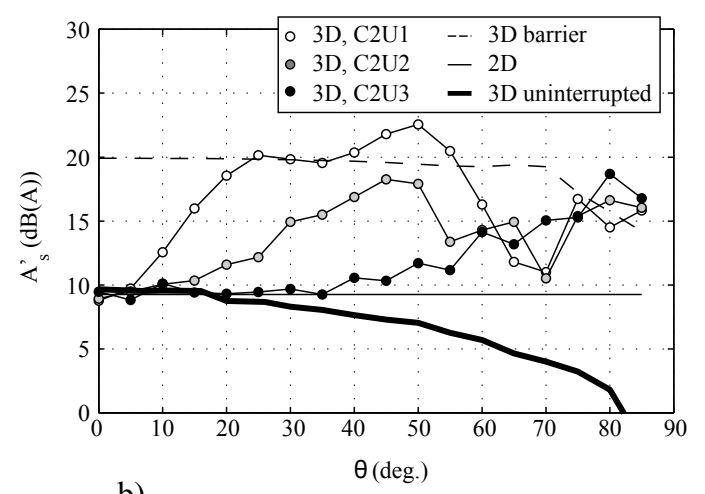

b)

Figure 13: Broadband values up to $1 \mathrm{kHz}$ at $Q=40 \mathrm{~W}$ for configurations (a) and (c) as depicted in Figure 2.

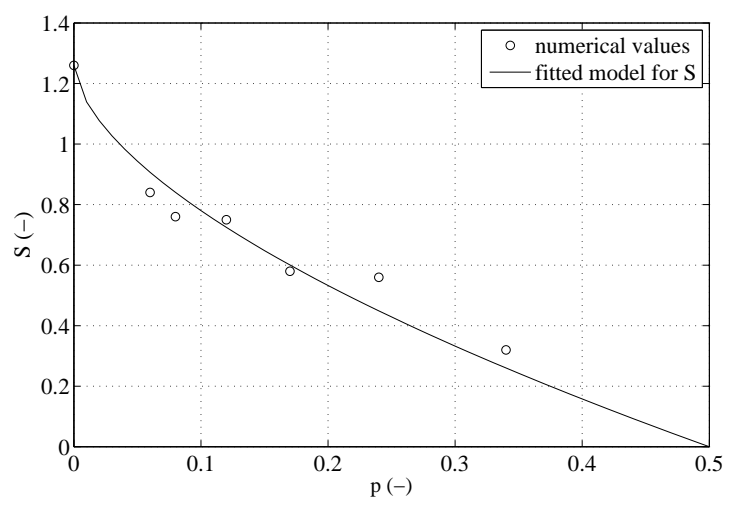

Figure 14: Angular averaged values of $S=\frac{\left(A_{\text {bars }}^{\prime}\left(\theta=0^{\circ}\right)-\bar{A}_{\mathrm{s}}^{\prime}\right)}{\left(A_{\mathrm{bar}, \mathrm{s}}^{\prime}\left(\theta=0^{\circ}\right)-A_{\mathrm{s}, 2 \mathrm{D}}^{\prime}\right)}$ for the various interrupted street configurations and the infinite street, $p$ is the angular fraction of façades openings in the horizontal plane as seen from the source. 


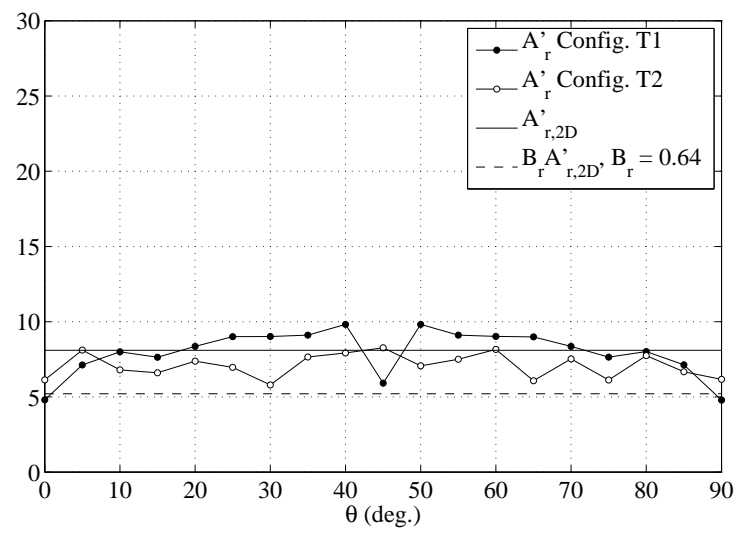

Figure 15: Broadband $A_{\mathrm{r}}^{\prime}(\theta)$ values up to $1 \mathrm{kHz}$ with source position at $Q=40 \mathrm{~W}$ for configuration (e) as depicted in Figure 2, and 2D result for $\theta=0^{\circ}$.

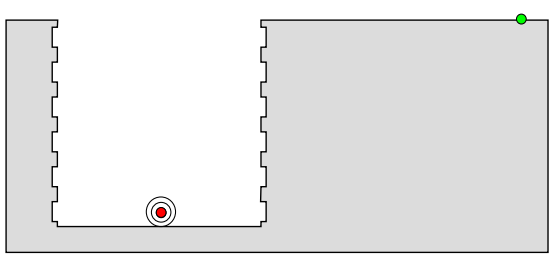

a)

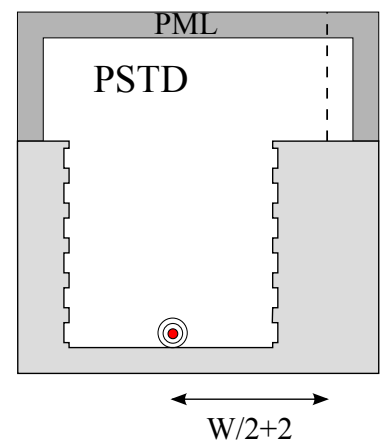

b)
KH-integral

Figure 16: Two-step numerical approach to solve configuration of a), b) Application of PSTD method to solve source region part, and evaluation of the KH-integral equation to solve the region over roof level height. 


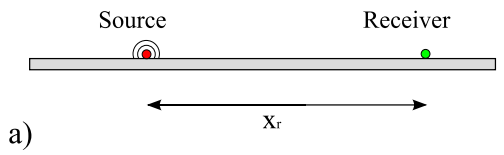

a)

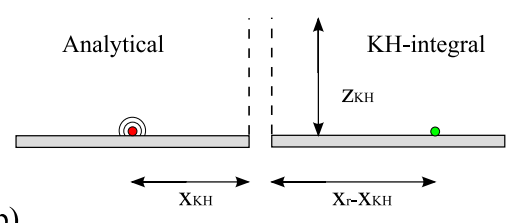

b)

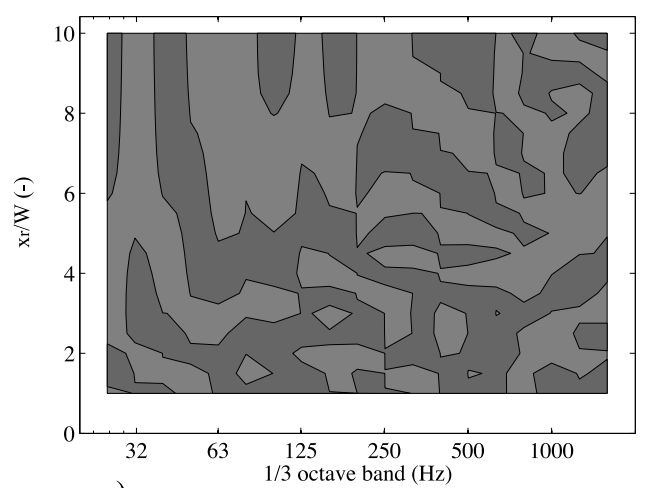

c)

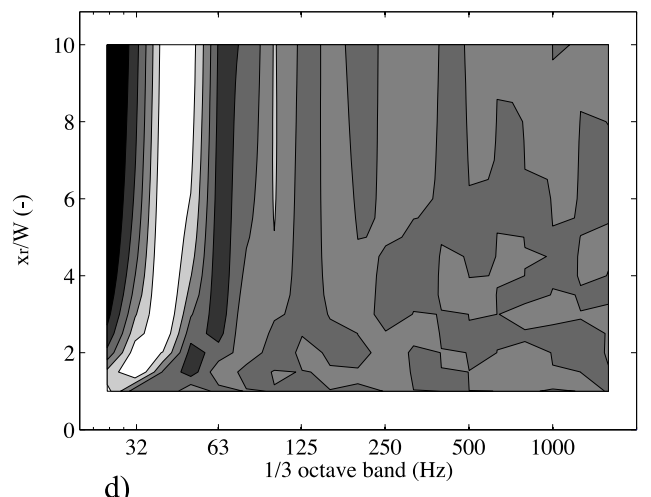

Rigid termination

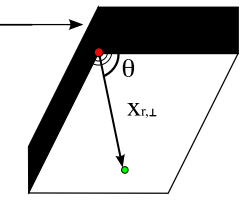

e)

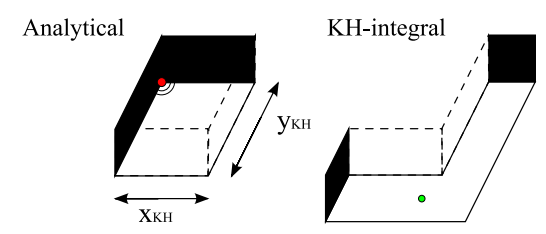

f)
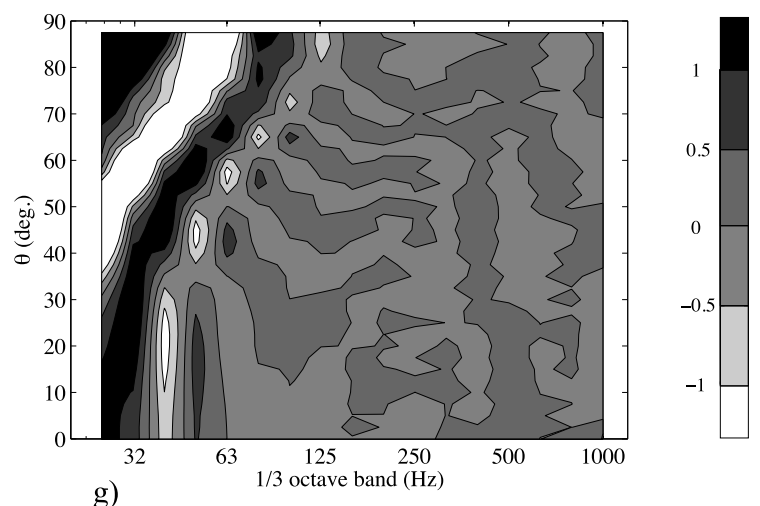

g)

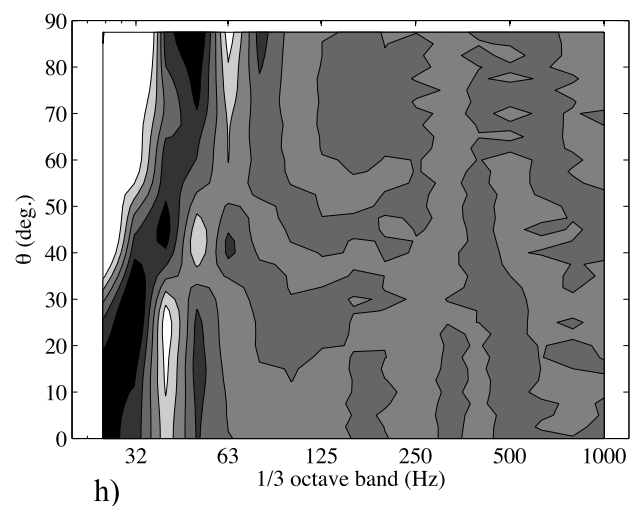

1
0.5
-0.5
-1

Figure 17: a) 2D configuration studied, b) Two-stage computational approach with analytical results at $x_{\mathrm{KH}}$ and KH-integral approach from $x_{\mathrm{KH}}=W / 2+2 \mathrm{~m}$ to receiver at $x_{r}$. c) Error of the KH-integral approach for $z_{\mathrm{KH}}=30 \mathrm{~m}$ for $W=19.2 \mathrm{~m}$, d) Error of the KH-integral approach for $z_{\mathrm{KH}}=30 \mathrm{~m}$ for $W=19.2 / \cos (\theta) \mathrm{m}$ and $\theta=80 \mathrm{deg}$., e) 3D configuration studied, f) Two-stage computational approach with analytical results at $x_{\mathrm{KH}}=W / 2+2 \mathrm{~m}$ and KHintegral approach to receiver at $x_{r, \perp}=20 W, W=19.2 \mathrm{~m}$, g) Error of the KH-integral approach for $z_{\mathrm{KH}}=30 \mathrm{~m}$ for $y_{\mathrm{KH}}=4 W$ according to configurations (c,d) of Figure 2. h) Error of the $\mathrm{KH}$-integral approach for $z_{\mathrm{KH}}=30 \mathrm{~m}$ for $y_{\mathrm{KH}}=3 W / 2+2 \mathrm{~m}$ according to configurations (e,f) of Figure 2 with $T=3 W / 2$. Errors in $\mathrm{dB}$. 